\title{
MERCADERES Y HOMBRES DE NEGOCIOS EN LA RIOJA A FINES DE LA EDAD MEDIA
}

\author{
Máximo Diago Hernando \\ Instituto de Historia. CSIC. Madrid
}

\section{La Rioja, tierra de mercaderes: La herencia del camino de Santiago y la frontera con Navarra}

Varios factores propiciaron que la región riojana se consolidase en el período bajomedieval como una encrucijada favorecida por el notable desarrollo experimentado por las actividades comerciales, que se tradujo en la presencia de dinámicos grupos de mercaderes en sus principales núcleos urbanos, quienes, a diferencia de sus homólogos de las principales ciudades castellanas de la meseta, lograron ocupar una posición preeminente en la jerarquía local, hasta el punto de llegar incluso a conformar un estamento diferenciado, el de los ciudadanos, que, en Logroño en particular, disfrutó de notable influencia en el terreno político ${ }^{1}$. Entre dichos factores cabe destacar en primer lugar el hecho de que la región fue atravesada por el Camino de Santiago, vía de comunicación de primer orden de la España medieval, a través de la que fluyeron multitud de personas y mercancías, y que gracias a ello hizo posible la intensificación de los intercambios entre los territorios de los reinos de Castilla y León y la Europa transpirenai-

1. Sobre la influencia alcanzada por el estamento de los ciudadanos en Logroño frente a los de los hidalgos y los labradores, que llegaron a aliarse para hacerle frente, vid. DIAGO HERNANDO, M., "Conflictos estamentales por el control del gobierno municipal en Logroño a fines del XV y principios del XVI", Cuadernos de Estudios Medievales y CC y TT Historiográficas, 17 (1992), pp. 205-25. Más referencias a la organización estamental de las ciudades riojanas, que presenta como una de sus principales peculiaridades la existencia de este estamento de los "ciudadanos" diferenciado del de los pecheros, bien constatada en Logroño y Nájera, Vid. GOICOLEA JULIÁN, F.J., "Concejos urbanos en la Rioja Alta a fines del Medievo: Aspectos institucionales y políticos", HID, 26 (1999), pp. 233-53. Y, El gobierno urbano en La Rioja en época medieval e inicios de la Edad Moderna (s. XIII-mediados del XVI), Logroño, 2004, pp. 15-38. 
ca. A lo largo de esta vía prosperaron, en efecto, a partir del siglo XI los asentamientos urbanos con decidida orientación mercantil, en los que con frecuencia se instalaron gentes procedentes del otro lado de los Pirineos, los Ilamados francos, muchos de ellos mercaderes. Sin duda alguna el núcleo urbano más favorecido por todo este proceso de intensificación de los intercambios que trajo consigo el desarrollo de las peregrinaciones a Santiago de Compostela, y la instalación de colonias de francos a lo largo del Camino que unía la tumba del Apóstol con el centro de Europa, fue la ciudad de Burgos, que logró auparse a la posición de principal metrópoli mercantil del norte de la Corona de Castilla, que mantuvo hasta las últimas décadas del siglo XVI. Pero, a escala más modesta, también cabe decir que los principales núcleos urbanos de la Rioja obtuvieron notable provecho del mismo, consolidándose gracias a él como importantes centros mercantiles, lugar de asentamiento de dinámicos grupos de mercaderes². Ciertamente a partir de los siglos XV y XVI la importancia del Camino de Santiago como ruta mercantil decayó de forma considerable, como también lo hizo el fenómeno de las peregrinaciones, al que le asestó un importante golpe el triunfo de la Reforma protestante en muchos países europeos, mientras que de forma paralela fue adquiriendo cada vez mayor relevancia el tráfico marítimo desde los puertos del Cantábrico, entre los que correspondió un protagonismo creciente al de Bilbao. Esta evolución no afectó, sin embargo, en un primer momento de forma apreciable a las comunidades de mercaderes que se habían establecido a lo largo del Camino de Santiago, encabezadas por la burgalesa, sino que por el contrario dichas comunidades lograron mantener durante mucho tiempo el control de los intercambios comerciales con el resto de Europa que ahora tendían a realizarse en cada vez mayor medida por vía marítima, dado que en las villas costeras desde las que operaban los barcos apenas había mercaderes con suficiente capacidad financiera y contactos como para plantear una seria competencia. Y, en efecto, cabe constatar que durante los siglos XV y XVI los mercaderes de las ciudades riojanas, a la sombra de los burgaleses, desempeñaron un papel nada desdeñable en el comercio internacional, como tendremos ocasión de comprobar a lo largo del presente trabajo, en particular al dar cuenta del comercio de exportación de lanas finas.

Además de por estar atravesada por el Camino de Santiago, la Rioja participó también durante el período bajomedieval de la condición de auténtica encrucijada de caminos por el hecho de compartir una larga línea fronteriza con el reino de Navarra. La condición de tierra fonteriza no siempre resultaba necesariamen-

2. Vid. RUIZ DE LA PEÑA, J.I., "La formación de la red urbana en el tramo riojano del Camino de Santiago y las colonizaciones francas (Siglos XI-XIII)", en Actas de la Reunión científica "El fuero de Logroño y su época", Logroño, 1996, pp. 211-30. Y MARTínEZ SOPENA, P., "Logroño y las villas riojanas entre los siglos XII y XIV", en Historia de la ciudad de Logroño, Logroño, 1994, vol. 2, pp. 279-322. 
te favorable para el fomento de la práctica comercial, pues la presencia de las aduanas introducía a veces un importante factor desestabilizador de los intercambios, al margen de que las frecuentes situaciones de guerra entre los reinos de Castilla y Navarra conllevaron evidentes riesgos para los mercaderes que se arriesgaban a viajar con sus mercancías a tierras del enemigo. Pero, a pesar de todo ello, no cabe duda de que el carácter de punto principal de entrada en Castilla desde Navarra que tuvieron algunas de las ciudades riojanas, en especial Logroño y Calahorra, contribuyó de forma muy positiva a canalizar a través de ellas importantes flujos del comercio internacional por vía terrestre, pues se ha de tener en cuenta que Navarra era, además, territorio de tránsito para las mercancías que la Corona de Castilla intercambiaba por vía terrestre con Francia. Y, en efecto, algunos testimonios documentales confirman que el tráfico de mercancías a través de la frontera alcanzó notable relevancia en estas ciudades. Es el caso en concreto de un apunte encontrado en la documentación hacendística de Simancas del año 1480 que recoge una estimación, según la cual, como consecuencia del mercado franco que se celebraba en Logroño, la hacienda regia dejaba de ingresar cada año 150.000 mrs. en concepto de impuestos aduaneros, debido a que "todos los de Navarra y Castilla y de todas partes sacan y meten sus mercancías, sin pagar diezmo, so color de venir al mercado" ${ }^{\prime 3}$.

La concesión por la monarquía, o por otros titulares del señorío jurisdiccional, de privilegios de exención de impuestos a ferias y mercados celebrados en los principales núcleos urbanos de la Rioja fue, en efecto, otro destacado factor que favoreció el desarrollo de la actividad mercantil en estas tierras. Pero, desde este punto de vista, no puede decirse que la Rioja resultase mucho más favorecida que otras comarcas castellanas de su entorno, en las que también proliferaron este tipo de concesiones ${ }^{4}$ Y de hecho cabe afirmar que ferias celebradas fuera del ámbito riojano, como es el caso de las de Medina del Campo, Medina de Ríoseco y Villalón, actuaron como poderosos polos de atracción de los más emprendedores mercaderes de las ciudades riojanas durante los siglos XV y XVI, mientras que en contrapartida las que tuvieron por sede estas ciudades no lograron en igual medida erigirse en polos de atracción de mercaderes de otras tierras, sino que por el contrario no superaron el radio de acción meramente local o comarcal.

\section{Los mercaderes riojanos en el comercio de la lana}

De todas las mercancías con las que negociaron los mercaderes que operaron en el territorio riojano a fines de la Edad Media la principal fue muy proba-

3. AGS(=Archivo General de Simancas), EMR (=Escribanía Mayor de Rentas), 37-353.

4. Una visión general sobre esta cuestión para el conjunto de la Corona de Castilla, que incluye referencias a las ferias y mercados celebrados en la Rioja, en LADERO QUESADA, $M$. A., Las ferias de Castilla. Siglos XII al XV, Madrid, 1994. 
blemente la lana, tanto por el volumen comercializado como por los beneficios que generó su trato. A partir de las primeras décadas del siglo $\mathrm{XV}$, en efecto, tuvo lugar un rápido incremento de las exportaciones de lana fina castellana a través de los puertos del Cantábrico, como consecuencia del desarrollo de una fuerte demanda de esta mercancía en los centros pañeros de los Países Bajos, donde las lanas castellanas fueron progresivamente sustituyendo a las inglesas como principal materia prima de la manufactura local. Estas lanas demandadas por el mercado flamenco eran prioritariamente las obtenidas del esquileo de los ganados trashumantes, de raza merina, aunque con carácter excepcional también está constatada la exportación de otras de inferior calidad, procedentes de ganados estantes o trasterminantes, es decir, de los que sólo realizaban desplazamientos de cortas distancias a lo largo del año.

La ubicación de la Rioja entre las comarcas serranas del sector septentrional del Sistema Ibérico, donde se concentraba una fracción importante de la cabaña ovina trashumante del reino de Castilla, por un lado, y los puertos del Cantábrico, donde se habían de embarcar para su exportación las lanas procedentes del esquileo de dicha cabaña, por otro, representó sin duda un factor decisivo para que los mercaderes asentados en esta región alcanzasen un notable protagonismo en el comercio de esta materia prima entre los siglos XV y XIX. Y, en efecto, hubo destacados mercaderes exportadores de lanas en las ciudades y villas riojanas en estos siglos, además de otros de menor talla que se especializaron en la compra de lanas a pequeños y medianos señores de ganados de las sierras cameranas para su posterior reventa a otros mercaderes foráneos, que se encargaban de su exportación.

Con ser importante el comercio de lanas finas de ganado trashumante, es decir, las identificadas en la documentación con el nombre de "estremeñas" fue, sin embargo, el único trato con lanas que alcanzó notable desarrollo en la región riojana a partir del siglo XV. Por otro lado tenemos constancia de que también se negoció intensamente con otro tipo de lanas de inferior calidad y precio para las que existía una importante demanda en la manufactura pañera castellana, especializada en la producción de paños de calidad media o baja. Se trata de las llamadas churras y riberiegas, procedentes del esquileo del ganado estante, que se mantenía durante todo el año en sus propios pagos, y del trasterminante, que era llevado en invierno a pastar a las tierras más cálidas del reino de Navarra, o del de Aragón ${ }^{6}$. Muchos mercaderes negociaron simultáneamente con

5. Sobre las denominaciones de los distintos tipos de lanas que fueron objeto de comercialización Vid. DIAGO HERNANDO, M., "El mercado lanero en la región soriana durante los siglos XVI y XVII: Tipología y destino de las lanas", Celtiberia, 96 (2002), pp. 47-88. Las mismas denominaciones que nos encontramos en la documentación soriana a aparecen en la de Rioja y Cameros.

6. Sobre la importancia alcanzada en los siglos XVI y XVII por el comercio de las lanas churras en la región soriana, desde la que se exportaron cantidades importantes hacia los talleres 
todos estos tipos de lanas, mientras que otros, por el contrario, tendieron a especializarse en el trato de algún tipo determinado. Pese a que en el estado actual de las investigaciones no disponemos de informaciones suficientes para conocer la identidad de los tratantes laneros que operaron en la región riojana en el siglo $\mathrm{XV}$ y durante la primera mitad del siglo XVI, por indicios cabe presumir que, al igual que ocurrió en otras regiones, como, por ejemplo, la soriana, sólo los mercaderes de más talla lograron abrirse camino en el negocio de la compraventa de lanas "estremeñas". Y, por el contrario, el número de los que negociaron con lanas churras fue mucho mayor, tratándose en la mayor parte de los casos de personas de posición más modesta, que a veces ni siquiera tenían como dedicación principal la de mercader, sino que desempeñaban una profesión artesanal o de otro tipo, y recurrían al trato con lanas para incrementar sus ingresos, mediante la diversificación de sus inversiones. Teniendo en cuenta estas circunstancias hemos preferido analizar por separado el comercio de las lanas "estremeñas" por un lado, y el de las "churras" y "riberiegas", por otro, pese a que hubo mercaderes que simultáneamente tomaron parte activa en ambos.

\subsection{El comercio de lanas "estremeñas"}

Para conocer en detalle el papel desempeñado por los mercaderes riojanos en el comercio de las lanas finas del ganado trashumante durante el siglo XV y gran parte de la primera mitad del siglo XVI tropezamos con el grave inconveniente de la escasez de fuentes documentales, y la falta prácticamente absoluta de estudios previos que hayan acometido la tarea de rastrear y analizar las pocas conservadas. Se impone, por tanto, la necesidad de abordar el estudio de esta cuestión con datos sumamente fragmentarios, que proporcionan indicios más o menos fiables, pero que raramente permiten alcanzar certezas absolutas.

Las pocas noticias que hasta ahora hemos logrado reunir nos confirman en cualquier caso que a fines del siglo XV los principales mercaderes de lanas estremeñas se concentraban en las ciudades de Nájera y Logroño, es decir las mismas en las que seguían estándolo durante la segunda mitad del siglo XVI, período relativamente mejor conocido desde esta perspectiva, pues para su estudio se dispone de una documentación más abundante, a la que además ya han dedicado su atención algunos investigadores en trabajos monográficos de notable interés.

pañeros de las villas cameranas, Vid. DIAGO HERNANDO, M., "El comercio de las lanas churras en el ámbito soriano durante el siglo XVI", Chronica Nova, 19 (1991), pp. 87-111. Y "El papel de la lana en las relaciones económicas entre Soria y las villas pañeras cameranas en los siglos XVI y XVII", Berceo, 138 (2000), pp. 61-90.

7. Sobre la importancia de Nájera como centro del comercio lanero, y lugar de asentamiento de destacados mercaderes exportadores, durante la segunda mitad del siglo XVI, Vid. BRUMONT, F., «La laine dans la région de Nájera (Deuxième moitié du XVle. Siècle) 》, en Actas del II Coloquio de Metodología Histórica Aplicada, Santiago de Compostela, 1983, pp. 318-32. 
En Nájera tenía fijada su residencia durante el reinado de los Reyes Católicos el doctor Alonso Martínez de Nájera, personaje de indudable relieve desde el punto de vista socieconómico, pues sabemos que murió siendo señor de Castroviejo, lugar que primeramente había pertenecido al linaje Estúñiga, y después a Juan de Leiva, caballero de quien él lo debió obtener por compra en fecha que de momento no hemos podido determinar ${ }^{8}$. Sobre su actividad como mercader lanero no es mucho lo que de momento hemos conseguido averiguar. Pero al menos tenemos certeza de que recurrió al procedimiento de concertar por adelantado la compra de sus lanas a pequeños y medianos propietarios de ganado trashumante de las aldeas serranas de los Cameros, efectuándoles adelantos de dinero para que pudiesen afrontar las necesidades de financiación de sus explotaciones. En concreto desde esta perspectiva hay que destacar por su singularidad el contrato que en 1499 firmó con el concejo de Brieva, villa camerana con fuerte vocación ganadera trashumante, por virtud del cual sus vecinos señores de ganado se comprometieron a venderle todas las lanas procedentes del esquileo de sus ovejas y carneros durante cuatro años, a contar desde 1499, con la condición de que él les había de entregar por adelantado cada año cien mrs. por arroba el día de Santiago, otros cien el día de San Miguel, y abonar el resto de su valor el día de San Pedro, es decir, nada más terminado el esquileo, ateniéndose al precio que hubiesen fijado dos árbitros, designados previamente por ambas partes. Durante los años 1499 y 1500 los ganaderos de Brieva respetaron el acuerdo, pero en 1501 ya no se mostraron dispuestos a cumplir lo capitulado, quizás porque algún otro mercader llegó a ofrecerles mejores condiciones para la compra de sus lanas. Y por ello el doctor de Nájera tuvo que ponerles demanda ante los tribunales ${ }^{9}$.

Esta noticia nos demuestra, por lo tanto, que este mercader najerense estaba en condiciones de invertir importantes cantidades de dinero en la compra por adelantado de sus lanas a pequeños y medianos señores de ganados trashumantes de las sierras cameranas, comprometiéndolos mediante importantes adelantos de dinero a la entrega del producto del esquileo de varios años seguidos, lo que no solía ser muy habitual en la época. Pero poco más podemos precisar sobre su volumen de negocios, ámbito geográfico de actuación o estrategias mercantiles. Nos hemos de contentar con dejar simplemente constancia de que, al menos, sabemos que era un mercader exportador. Así nos lo confirma en concreto un documento del año 1503 que recoge una denuncia por él presentada contra el Condestable de Castilla, perceptor en aquellos momentos por real pri-

8. AGS, RGS(=Registro General del Sello), III-1506, fol. 98. Carta de seguro para el concejo de Castroviejo, que se temía de la viuda y herederos del doctor de Nájera, señor del lugar, con quienes trataba pleito sobre restitucion de la posesión de los términos.

9. Noticia del pleito que se seguía entre ambas partes con este motivo en AGS, RGS, VII1501. 
vilegio del impuesto aduanero de los "diezmos de la mar", que debían abonar todas las mercancías que pasaban por los puertos del mar Cantábrico ${ }^{10}$. Se quejó, en efecto, nuestro personaje de que, a pesar de que él era miembro de la cofradía de mercaderes de la ciudad de Burgos, con la cual el Condestable había firmado cierto asiento sobre la cuantía de dinero que éstos habían de pagarle en concepto de "diezmos de la mar" por sus operaciones mercantiles, éste le exigía a él que pagase más de lo que le correspondía, como miembro de la cofradía ${ }^{11}$. No aclara ciertamente este documento por qué mercancías estaba obligado a abonar el doctor Alonso Martínez de Nájera los "diezmos de la mar" al Condestable, pero la probabilidad de que entre ellas figurase la lana es grande.

Nada más sabemos, en cualquier caso, sobre la identidad de otros vecinos de la ciudad de Nájera que pudieron estar interesados por estas mismas fechas en el comercio de lanas de ganado trashumante, pero consideramos muy probable que los hubiese, máxime teniendo en cuenta que esta población era entonces la capital del estado señorial de los duques de Nájera, que integraba un extenso espacio serrano con fuerte vocación ganadera trashumante, a cabaIlo entre las actuales provincias de Rioja y Soria, en el que se encontraban núcleos como San Pedro Manrique, Lumbreras, Ortigosa y Villoslada, donde eran muchos los vecinos que disponían de lanas finas para vender.

Noticias algo más abundantes, aunque también insuficientes, poseemos para determinar la identidad de algunos de los mercaderes avecindados en Logroño que destacaron por su participación en el comercio de lanas finas de ganado trashumante a fines del siglo XV y comienzos del siglo XVI. Entre ellos cabe mencionar en primer lugar a un tal Rodrigo de Ruego, quien hacia 1488 compró ciento cuarenta sacas de lana a Martín González de Yanguas, contador del conde de Aguilar, y a Miguel Sánchez, su primo, con la intención de exportarlas ${ }^{12}$.

Otros mercaderes que compartieron con Rodrigo de Ruego el interés por la adquisición de sacas de lana en la villa soriana de Yanguas, integrada en el estado señorial de los Arellano, señores de Cameros y condes de Aguilar, y que mantuvo una intensas relaciones con Logroño a lo largo de los siglos XV, XVI y XVII, fueron los hermanos Sancho y Antonio de los Arcos. Nos consta, en efecto, que ambos concertaron en la década de 1490 con Pedro González de Río, uno de los principales ganaderos del partido mesteño soriano en aquellos

10. Sobre la percepción por el Condestable de los "diezmos de la mar" Vid. FRANCO SILVA, A., "Los Condestables de Castilla y la renta de los diezmos de la mar", En la España Medieval, 12 (1989), pp. 255-84.

11. AGS, RGS, VI-1503. Provisión al corregidor de Burgos.

12. AGS, RGS, IV-1488, fol. 89. Provisión dirigida a los justicias de Yanguas, para que determinen la demanda de Rodrigo de Ruego. Vid. también CANTERA MONTENEGRO, E., "La adaptación de la sociedad logroñesa a la crisis bajomedieval. Las minorías", en Historia de la ciudad de Logroño. Edad Media, t. II, Logroño, 1994, p. 420. 
momentos, que residía en Yanguas al servicio de los condes de Aguilar ${ }^{13}$, la compra de cierto número de sacas de lanas y añinos por un valor que ascendía a 419.452,5 mrs. que le habían de abonar en varios plazos. Las condiciones del contrato de venta, por virtud del cual el ganadero vendedor concedió aplazamiento de pago a los mercaderes compradores, permiten presumir que la posición financiera de estos últimos no era muy holgada. Y de hecho así se demostró, puesto que, una vez vencidos los plazos de pago fijados en el contrato de obligación que ambas partes firmaron ante notario, Pedro González de Río terminó compareciendo ante la justicia ordinaria de Logroño, para denunciar que Sancho Martínez de los Arcos le continuaba adeudando 335.000 del total de 419.452,5 mrs. que debía abonarle por el valor de las sacas de lanas y añinos que le había vendido. Como consecuencia este mercader fue Ilevado preso a la carcel pública de Logroño, no sin antes haber alegado en su defensa que Pedro González de Rio le había vendido las sacas de lana y añinos con usura, exigiéndole por ellas un precio excesivo, como consecuencia de lo cual habia perdido su hacienda ${ }^{14}$. Con toda seguridad había exageración interesada en esta declaración, pero lo que sí consideramos probable es que el precio fijado por las sacas de lana y añinos en el contrato firmado con Pedro González de Río fuese más elevado que el habitual en operaciones de pago al contado, por no hablar de aquéllas en que el mercader adelantaba dinero a los ganaderos, precisamente para compensar al vendedor por la demora en el cobro del valor de la mercancía. De aquí deducimos que los hermanos Sancho y Antonio de los Arcos no eran mercaderes con sobrados recursos financieros, sino que, más bien al contrario, dependían en gran medida del crédito que les pudiesen conceder sus proveedores de lanas para poder negociar con esta mercancía. Y a esta misma conclusión nos lleva la constatación del hecho de que no fue al ganadero Pedro González de Río al único que denunciaron por haberles vendido sacas de lana con usura, puesto que por estas mismas fechas también lanzaron una acusación semejante contra Juan de Fuenmayor, vecino de Albelda, quien, como indicaremos más adelante, era un intermediario quien se dedicaba a la compra de pequeñas partidas de lanas para su posterior reventa a otros mercaderes ${ }^{15}$.

Otro mercader vecino de Logroño que sabemos que se interesó por la compra de lanas en la región soriana fue Pedro de Enciso. En concreto disponemos de una relación detallada de operaciones de compra por él realizadas en los años 1508 y 1509 en la villa de Ágreda y en varias aldeas de su Tierra, como

13. Sobre esta importante familia de ganaderos mesteños Vid. DIAGO HERNANDO, M., "Estrategias de ascenso social en la Castilla del siglo XVI. La familia Río en Soria", Historia Social, 49 (2004), pp. 3-27.

14. AchV (=Archivo de la Chancillería de Valladolid), RE(=Registro de Ejecutorias), VI-1498, leg. 63.

15. AGS, RGS, X-1496, fol. 203. Comisión al corregidor de Logroño. 
Ólvega, Castilruiz y Matalebreras ${ }^{16}$. En el primer ejercicio adquirió lanas y añinos de un total de 25 individuos diferentes, y al año siguiente de 37 . En muchos casos se trató de operaciones de escasa envergadura, pero también negoció con señores de ganados propietarios de grandes cabañas, como es el caso, por ejemplo, de Juan Garcés, vecino de Ágreda, quien en 1508 le vendió 2.125 vellones de lana, o la viuda e hijos de un bachiller vecino de Ólvega, quienes en 1508 le vendieron 3.100 vellones y en 1509 2.205. Dadas las grandes diferencias en los precios que abonó a los distintos vendedores, que van desde 45 hasta 20 mrs. por vellón, se impone, no obstante, la conclusión de que adquirió lanas de muy diversas calidades, entre las que habría lanas churras de ganado estante, las más baratas, lanas riberiegas de ganado trasterminante, las de precio intermedio, y lanas finas o "estremeñas", procedentes del esquileo de los ganados trashumantes, que eran las que alcanzaban los precios más elevados, y que adquirió en su mayor parte de vecinos de la villa de Ágreda, donde se concentraban los principales ganaderos trashumantes de la comarca.

Es seguro, por tanto, que este mercader logroñés se interesó por el trato con todo tipo de lanas, pues, por otra parte, también tenemos constancia de que, varios años más tarde, un individuo con este mismo nombre, que consideramos probable que sea la misma persona, efectuó compras de lana churra de cierta envergadura en Alfaro, en concreto una partida de mil lanas a Salvador Valles, vecino de dicha villa ${ }^{17}$. No es mucho, sin embargo, lo que sabemos con certeza sobre el papel que desempeñó en el comercio de lanas finas de ganado trashumante. A este respecto nos hemos de limitar a hacer constar que mantuvo relaciones de negocios con mercaderes burgaleses como Andrés Escobar que manifestaron un fuerte interés por el trato con este género de lanas en la región soriana ${ }^{18}$. Y en este contexto también interesa hacer refe-

16. Tomamos la información de AChV, P.C. Ceballos-Escalera, F. leg. 148. La relación de operaciones de compra realizadas por Pedro de Enciso, con indicación del nombre del vendedor, número de lanas vendidas, y precio abonado por lana, puede consultarse en DIAGO HERNANDO, M., "El comercio de las lanas en Soria en época de los Reyes Católicos", Celtiberia, 78 (1989), pp. 59-62.

17. Vid. GOICOLEA JULIÁN, F. J., "Alfaro a fines del Medievo e inicios de la Edad Moderna: Dinámica institucional y social en un núcleo urbano riojano fronterizo", Graccurris, 17 (2006), pp. 78-9. Dado el precio abonado, 30 mrs. por lana, no cabe duda de que debía tratarse de lana churra.

18. AGS, RGS, XII-1499, fol. 138. Emplazamiento a Pedro de Enciso a petición de Andrés de Escobar, vecino de Burgos, sobre apelación de sentencia pronunciada por Alvar Sánchez de Medina, juez comisario, contra Andrés de Escobar. Sobre los intereses de este mercader burgalés en el comercio de lanas de la región soriana Vid. DIAGO HERNANDO, M., "El comercio de las lanas en Soria en época de los Reyes Católicos", Celtiberia, 78 (1989), pp. 25-75. Y "Efectos del decreto de expulsión de 1492 sobre el grupo de mercaderes y financieros judíos de la ciudad de Soria", en ROMERO, E. (Ed.), Judaísmo hispano: Estudios en memoria de José Luis Lacave Riaño, Madrid, CSIC, 2002, pp. 749-764. 
rencia a sus tratos con otros mercaderes burgaleses de la familia Pardo. En concreto cabe recordar que Alonso Pardo otorgó en Brujas el 7 de septiembre de 1515 una cédula de cambio por la que ordenó a Diego Pardo, mercader vecino de Burgos probablemente pariente suyo, que abonase a Pedro de Enciso 200 ducados de oro, la cual fue presentada al protesto ante un notario de Medina del Campo el 22 de noviembre de ese año, porque no se pudo localizar a Diego de Pardo en esta villa vallisoletana para que cumpliese con el pago de la referida cantidad ${ }^{19}$. Lamentablemente el documento no aclara cuál era el motivo por el que se había de abonar a este mercader logroñés dicha cuantía de dinero. Cabe la posibilidad de que hubiese enviado lanas a Flandes para que Alonso Pardo se las vendiese en su nombre, y ahí radicase el origen de la deuda, pero también resultan igualmente verosímiles otras explicaciones.

Por otra parte, también tenemos constancia de que Pedro de Enciso tuvo a su servicio a agentes instalados en la ciudad flamenca de Brujas que eran originarios de Logroño, y en algún caso incluso parientes suyos. Así, sabemos que en 1521 residían allí su hermano Juan de Enciso, y Hernando de Orozco, a quien en un documento identifica explícitamente como su "factor" ${ }^{20}$. No conocemos bien el tipo de negocios que estos dos individuos realizaban en su nombre en aquella plaza, principal centro de contratación de lanas de Flandes. Sí tenemos constancia, no obstante, de que en ocasiones se hacían cargo del pago de determinadas cantidades de dinero que Pedro de Enciso, u otros mercaderes de Logroño con los que mantenían relaciones de negocios, tomaban a préstamo en las ferias de Medina del Campo o de Medina de Ríoseco, como Bartolomé de Poza o Diego de Enciso, con la condición de que habían de ser devueltas en Flandes. Así, por ejemplo, en Medina del Campo, el 10 de diciembre de 1521, Pedro de Enciso y Bartolomé de Poza recibieron prestadas del mercader burgalés Antonio de Nájera 1.000 coronas de oro, que se obligaron a devolver dando orden por medio de cédulas de cambio a Hernando de Orozco para que las pagase mediada la Cuaresma de 1522 a un vecino de Brujas Ilamado Antonio de Nájera. El mismo procedimiento se contempló para devolver otras 1.000 coronas que recibieron prestadas del burgalés Sebastián de Salamanca, otras 1.659 que les prestó el burgalés Diego de Medina, y otras 1.300 que obtuvie-

19. AHPV (=Archivo Histórico Provincial de Valladolid), 7839-312, Medina del Campo, 22$\mathrm{XI}-1515$.

20. En carta de poder otorgada en Logroño, 17-XI-1521 por Pedro de Enciso, el mozo, indica que Juan de Enciso, su hermano, reside en Flandes. En otra carta otorgada en esa misma fecha Pedro de Enciso identifica a Hernando de Orozco como "mi factor que reside en Flandes". Ambas cartas de poder en AHPV, 7841. En 1527 Hernando de Orozco había pasado a residir a Amberes, donde debía seguir al servicio de Pedro de Enciso, que le encargaba de efectuar pagos en dicha plaza por cantidades de dinero que él tomaba prestadas en Medina del Campo. Un ejemplo en AHPV, 7845-321. 
ron del bilbaíno Diego de Vasurto Villasante ${ }^{21}$. Y, por fin, Diego de Enciso y Bartolomé de Poza, también concertaron este mismo año unas operaciones de idéntica naturaleza en la plaza de Medina de Ríoseco, tomando prestadas cantidades de dinero de mercaderes burgaleses y genoveses, con la condición de que Juan de Enciso y Hernando de Orozco las devolverían en Flandes ${ }^{22}$. No podemos entrar aquí a interpretar el sentido de estas operaciones, en las que se combinaba el elemento crediticio con el de las compensaciones de pagos entre la Corona de Castilla y Flandes, pero en cualquier caso consideramos que ponen de relieve la intensidad de los contactos que Pedro de Enciso mantuvo con este último territorio. Y, ante esta constatación, creemos que no hay motivo para dudar que este mercader logroñés fue un activo exportador de lanas al mercado flamenco, en el que los factores de origen logroñés que allí tenía a su servicio se encargarían de venderlas a fabricantes pañeros o a otros mercaderes intermediarios.

Otras dos destacadas familias logroñesas, emparentadas entre sí, que nos consta que participaron activamente en el trato con lanas estremeñas, fueron las de los Soria y los Yanguas, respecto a las cuales los datos que poseemos por el momento son, no obstante, bastante más tardíos, aunque muy elocuentes, pues demuestran que su volumen de negocio llegó a ser en determinados ejercicios muy elevado. En concreto cabe destacar por su gran envergadura la operación que en 1546 concertaron los hermanos Diego y Antonio de Yanguas con Antón de Río, el menor, regidor de Soria, nieto del Pedro González de Río, vecino de Yanguas, al que hemos hecho referencia con anterioridad. Era este individuo uno de los mayores propietarios de ganados trashumantes de la cuadrilla mesteña soriana en aquellos momentos, y esta circunstancia explica que se encontrase en disposición de vender a los dos referidos mercaderes logroñeses la astronómica cifra de 11.977 arrobas de lana, procedentes del esquileo de sus propios rebaños, por supuesto de más de un ejercicio, y de los de su tío Juan de Río, también regidor de Soria. El precio por arroba que se fijó en el contrato de venta fue por otro lado bastante alto, de 680 mrs. por arroba, lo cual nos da idea de la importante movilización de recursos financieros que conllevó la operación. Pero, por si esto fuera poco, también sabemos que al mismo tiempo estos dos mercaderes logroñeses adquirieron a Antón de Río 93 sacas de lana lavada a un precio de $8.250 \mathrm{mrs}$. por saca, las cuales este ganadero había adquirido previamente de Diego Sanz, mercader vecino de Soria ${ }^{23}$.

21. Los contratos de cambio, como se llamaba a estas operaciones de préstamo camufladas, fueron concertados por poderes por Baltasar de Vendigar y Caso de León, en Medina del Campo, 10 y 11 de diciembre de 1521. AHPV, 7841-190, 191, 193, 194 y 195.

22. AHPV, 8434, Medina de Ríoseco, 9 y 10-IX-1521.

23. Tomamos la información de AChV, P.C. (=Pleitos Civiles), Pérez Alonso, F.(=Fenecidos) C. 602-7. 
No fue, en cualquier caso, ésta la única operación de compra de lanas que esta familia de mercaderes logroñeses concertó con la acaudalada familia ganadera de los Río, originaria de Yanguas y que había trasladado su residencia a Soria hacia el año 1520. Por el contrario, nos consta que con anterioridad, en 1532, Diego de Yanguas ya había adquirido lanas de Juan de Río, tío del Antón de Río al que acabamos de referirnos, por valor de 500.000 mrs. ${ }^{24}$. Por otra parte, también tenemos noticia de otras operaciones de compra de lanas estremeñas de cierta envergadura realizadas por este mercader juntamente con su cuñado Hernando de Soria. En concreto en 1535 ambos adquirieron 930 arrobas de Hernando Sáenz, vecino de Yanguas, a quien pagaron por ellas 409.200 mrs., es decir, a razón de 440 mrs. por arroba ${ }^{25}$, y en 1542 compraron una partida de lanas de algo más de 1.000 arrobas a Enrique de Arellano y María López de Prado, vecinos de Viniegra de Yuso ${ }^{26}$. Por ello entendemos que estos individuos se debieron contar entre los más activos tratantes laneros de las sierras cameranas y sorianas durante la primera mitad del siglo XVI, aunque convendría profundizar bastante más en el rastreo de nuevas fuentes documentales para tratar de determinar en qué medida se involucraron en empresas de exportación ${ }^{27}$, y si mantuvieron estrechas y regulares relaciones de negocios con mercaderes de origen castellano residentes en Flandes, Bretaña o Normandía, o incluso en Italia. A este respecto sólo cabe recordar que en 1521 los hermanos Hernando y Rodrigo de Soria estaban relacionados con dos individuos, al parecer de origen logroñés, residentes en Brujas, Ilamados Antonio Hernández y Antonio de Soria, a quienes dirigían cédulas de cambio para que pagasen determinadas cantidades de dinero a otros individuos de origen castellano residentes en aquella misma ciudad flamenca, para devolver por esta vía las cantidades que ellos recibían prestadas en Medina del $\mathrm{Campo}^{28}$.

24. GOICOLEA JULIÁN, F. J., "La élite ciudadana de Logroño...", pp. 119-20.

25. Íbid. p. 121.

26. AChV, P.C. Fernando Alonso, F. C. 1142-4.

27. De la participación de Diego y Antonio de Yanguas en negocios de exportación da fe su inclusión en la relación de personas que en 1547 tenían relación con Martín de Bertendona, mercader vecino de Bilbao, quien les servía de encomendero a ambos, entre otros muchos, en dicha villa portuaria. Tomamos la noticia de ANGULO MORALES, A., "En poco tiempo vienen ricos e hazen a sus amos pobres. De factores o encomenderos a protagonistas directos del gran comercio internacional (siglos XV-XVII)", en GARCÍA FERNÁNDEZ, E. (Ed.), Bilbao, Vitoria y San Sebastián: Espacios para mercaderes, clérigos y gobernantes en el Medievo y la Modernidad, Universidad del País Vasco, Bilbao, 2006, pp. 108 y ss.

28. Vid. AHPV, 7841, Medina del Campo, 7-XII-1521. Antonio de Yanguas, con poder de los hermanos Hernando y Rodrigo de Soria, tomó prestadas de Sebastián de Salamanca, mercader vecino de Burgos, mil coronas de oro, que serían pagadas para mediada la próxima Cuaresma de 1522 a Antonio de Nájera, vecino de Brujas, por Antonio Hernández y Antonio de Soria, estantes en Brujas. 
Otro mercader logroñés que se interesó por el trato con lanas estremeñas, y que, por sus vínculos de negocios con el puerto de Bilbao presumimos que pudo involucrarse directamente en su exportación, fue Juan Fernández de Navarrete $^{29}$, quien nos consta que, actuando en compañía con sus convecinos Alonso el Rojo y Diego de Villoslada, adquirió en 1529 una partida de de este género de lanas en la villa soriana de Ágreda a uno de los principales señores de ganados de la localidad, Pedro Díaz de Fuenmayor, por valor de 365.011 mrs., que se obligó a hacerle efectivos en varios plazos $^{30}$.

Otros tratantes residentes en territorio riojano en esta época, según todos los indicios, se limitaron por el contrario a actuar como meros intermediarios, que compraban de forma preferente a pequeños y medianos propietarios de ganado tanto trashumante como estante, para luego revender las partidas de lana que de este modo lograban reunir a otros mercaderes, bien riojanos o bien de otras procediencias, pero que en ningún caso se aventuraban en el arriesgado negocio de la exportación, que exigía disponer de contactos fuera del país y estar bien integrado en las redes del comercio internacional. Con las informaciones que hemos logrado reunir hasta ahora no resulta fácil, sin embargo, determinar cuáles de estos intermediarios revendedores tuvieron activa participación en el trato con lanas estremeñas, y cuáles se limitaron a negociar con lanas de ganado estante y trasterminante, para las que existía una importante demanda en la manufactura pañera castellana. Y, por ello, hemos preferido no establecer distinciones entre ellos, procediendo a su identificación en el apartado dedicado a tratar del comercio de las lanas churras y riberiegas, por el que todos estos mercaderes revendedores mostraron un fuerte interés, incluidos aquéllos que también realizaron importantes inversiones en la adquisición de lanas "estremeñas".

Antes de concluir este apartado consideramos necesario llamar la atención, no obstante, sobre el hecho de que durante el período aquí analizado, es decir, las últimas décadas del siglo XV y las primeras del siglo XVI, no hemos podido constatar la existencia de destacados mercaderes de lanas "estremeñas", con intereses incluso en el negocio de la exportación, fuera de los principales núcleos urbanos de la región. Por contraste sabemos que en fechas posteriores, en la segunda mitad del siglo XVI y durante el siglo XVII, los hubo también, y muy importantes, en lugares de la sierra de marcado carácter rural, como Torrecilla o Lumbreras, donde combinaron el comercio lanero con otras actividades como la fabricación de paños, en el caso de los de Torrecilla, o la cría de ganados trashumantes y el tra-

29. Vid. ANGULO MORALES, A., art. cit. Menciona a Juan Fernández de Navarrete entre los que trabajaban con los encomenderos Pedro y Juan Benero, vecinos de Bilbao, entre 1565 y 1572.

30. AHPS (=Archivo Histórico Provincial de Soria), PN (=Protocolos Notariales), 1491-2231, Ágreda, 25-VI-1529. Escritura de obligación otorgada por Francisco de Navarrete, vecino de Logroño, en nombre de Juan Fernández de Navarrete, Alonso el Rojo, y Diego de Villoslada, vecinos de Logroño. 
to con otras mercancías como el cuero, en el de los de Lumbreras. Esta proliferación de grandes mercaderes laneros en ámbitos rurales en esa época no constituyó, sin embargo, un fenómeno exclusivo del territorio de la actual comunidad autónoma riojana, sino que también lo hemos podido constatar con igual grado de intensidad en el sector soriano de estas mismas sierras del Sistema Ibérico, muy en particular en el ámbito de la Tierra de Yanguas, donde a partir de las últimas décadas del siglo XVI unas cuantas familias campesinas desplegaron una intensa actividad en el comercio de lanas de ganado trashumante ${ }^{31}$.

\subsection{El comercio de lanas "churras y riberiegas"}

Junto al comercio de la lana fina del ganado trashumante, también experimentó un notable desarrollo en tierras riojanas durante los siglos XV y XVI el de las lanas procedentes del esquileo del ganado estante y trasterminante o riberiego, es decir el que era llevado a pastar en invierno a Navarra o Aragón. Se trataba de fibras de inferior calidad a la de las obtenidas del esquileo del ganado trashumante, y por este motivo no existía para ellas una fuerte demanda en los mercados exteriores. No obstante, conviene precisar que dentro de este tipo de lanas había establecidas importantes diferencias, en función del cuidado que los ganaderos pusiesen en la mejora de la raza de sus rebaños, pudiéndose dar el caso de que algunos grandes propietarios de ganados de raza churra dispusiesen de lanas de elevada calidad, que se les abonaban a precios relativamente elevados. De hecho algunas referencias aisladas encontradas en la documentación del siglo XVI prueban que, en ocasiones, lanas calificadas expresamente como "churras" o "riberiegas" fueron también objeto de exportación, pudiéndose presumir que el nivel de calidad de éstas era bastante superior a la media. Pero en el estado actual de las investigaciones resulta imposible determinar hasta qué punto esta práctica estuvo extendida, y quiénes fueron los principales proveedores de estas lanas "churras" y "riberiegas" que se exportaban. En cualquier caso, la proporción de este tipo de lanas destinada a la exportación debió ser en todo momento muy pequeña, pues la mayor parte fueron adquiridas por los fabricantes pañeros castellanos, que utilizaban básicamente este tipo de lanas para la manufactura de sus paños. Y tales pañeros Ilegaron a ser muy numerosos en la propia región de los Cameros y Rioja, donde alimentaron una importante demanda para este tipo de lanas, aunque para la época que aquí estamos analizando, las décadas finales del siglo XV y las primeras del siglo XVI, no disponemos apenas de información sobre la identidad de sus proveedores de materia prima.

31. Vid. DIAGO HERNANDO, M., "Mercaderes propietarios de ganado trashumante en la cuadrilla mesteña soriana en los siglos XVI y XVII", Studia Historica. Historia Moderna, 26 (2004), pp. 255-282. Y "Comerciantes campesinos en la Castilla bajomedieval y moderna: La actividad mercantil de los yangüeses entre los siglos XIV y XVII", Historia. Instituciones. Documentos, 32 (2005), pp. 115-144. 
La mayor parte de las noticias que hemos logrado reunir para esta época sobre el trato de lanas churras hacen referencia a los mercaderes que negociaban con este producto, bien adquiriéndolo directamente de los ganaderos, o bien a otros mercaderes que actuaban como intermediarios. Pero no suelen aclarar cuál era el destino final que tales mercaderes pretendían dar a dichas lanas. Salvo en los casos en que éstas, a veces mezcladas con "estremeñas", eran revendidas a mercaderes burgaleses, cabe presumir que los destinatarios de las mismas fueron fabricantes pañeros de la propia región de los Cameros y Rioja. Pero las fuentes consultadas apenas aclaran nada sobre la identidad de los mismos, y sobre las condiciones en que se les vendían las lanas.

Los mercaderes que se interesaron por el negocio de la compra de lanas a pequeños y medianos ganaderos para revenderlas a otros mercaderes, bien de la propia Rioja o de fuera de ella, los encontramos en puntos muy diversos de la geografía riojana, y no sólo en los principales núcleos urbanos a los que nos hemos referido hasta ahora. Por supuesto, los hubo en número relativamente importante en estos grandes núcleos, y muy en particular en Logroño. No estamos en condiciones de ofrecer una nómina detallada de los tratantes laneros residentes en esta ciudad que negociaron preferentemente con lanas churras a fines del siglo XV y principios del siglo XVI. Pero a título ilustrativo mencionaremos unos pocos nombres. En concreto a la familia Moreno, una de las principales del estamento ciudadano logroñés, pertenecía Pedro Moreno, quien negoció con ganaderos de cierto relieve social, pero que, según todos los indicios, no practicaban la trashumancia, como Juan de Vidaurreta, alcaide de Arnedillo, con quien concertó por adelantado la compra de sus lanas del esquileo de 1517, por las que le entregó 32.000 mrs. en concepto de señal ${ }^{32}$. Con este mismo tipo de propietario ganadero tuvo tratos otro mercader logroñés, Diego de Ribera, quien nos consta que llegó a solicitar que se hiciese ejecución en bienes de Juan de Lezana y su esposa Catalina, miembros de la familia que ostentaba el señorío jurisdiccional sobre la villa de Robres del Castillo, por el valor de 800 lanas que les había comprado a precio de 40 mrs. y que al parecer no le habían entregado ${ }^{33}$.

32. AGS, RGS, VIII-1517. Provisión a los alcaldes de Arnedillo, para que examinasen la denuncia presentada por Pedro Moreno, quien acusó al alcaide de Arnedillo de haber vendido a otro sus lanas, después de haberse concertado con él y de haber recibido $32.000 \mathrm{mrs}$. de señal.

33. AGS, Cámara-Memoriales, 139-43. Memorial de Diego López y Pedro Andrés, vecinos de Robres, presentado en Logroño, 27-VII-1521, en el que hacen constar que estando el rey Fernando el Católico en la villa de Robres, el doctor Cornejo mandó hacer ejecución en bienes de Juan de Lezana y su esposa Catalina, a petición de Diego de Ribera, vecino de Logroño, por cuantía de 800 lanas a 40 mrs. Otras noticias sobre compras de pequeñas cantidades de lana efectuadas por Diego de Ribera en 1535 en Villamediana y Sojuela en GOICOLEA JULIÁN, F. J., "Mercaderes y hombres de negocio: El poder del dinero en el mundo urbano riojano de fines de la Edad Media e inicios de la Edad Moderna", Hispania, 227 (2007), p. 962. 
Otros destacados mercaderes vecinos de Logroño de los que tenemos constancia que se interesaron por el trato con lanas churras, aunque a partir de noticias más tardías, fueron varios miembros de la familia Yanguas, de entre los que cabe destacar a Antonio de Yanguas, quien, por ejemplo, en 1535 concertó varias operaciones de compra de este género de lanas con pequeños y medianos propietarios de diversas villas y aldeas riojanas tales como Quel, Ocón y Autol $^{34}$. También logroñés era Pedro de Angulo, quien en 1521 denunció que los invasores franceses le habían robado 45 sacas de lana que tenía almacenadas en Murillo de Río Leza ${ }^{35}$. Y a estos nombres cabría sin duda añadir muchos otros más, tras haber llevado a cabo una exploración más sistemática de la documentación disponible, pues el trato con lanas churras estaba abierto a un espectro social mucho más amplio que el trato con lanas estremeñas, dado que no exigía inversiones tan importantes de dinero y conllevaba habitualmente menos riesgos. Por ello no resultó infrecuente que incluso determinados artesanos invirtiesen en él, como hemos podido comprobar reiteradamente en nuestras investigaciones dedicadas a la ciudad de Soria. Con toda probabilidad algo parecido debió ocurrir en Logroño, si bien en el estado actual de la exploración de la documentación no resulta posible demostrarlo mediante la aportación de ejemplos concretos.

Tratantes de lanas churras los hubo, no obstante, además de en los grandes núcleos urbanos, en otras muchas poblaciones de segundo rango de la geografía riojana. Así, por ejemplo, en la villa de Albelda estaba avecindado Juan de Fuenmayor, individuo que nos consta que efectuaba adelantos de dinero a ganaderos de muy diverso perfil social con la condición de que se lo devolviesen mediante la entrega de sus lanas del próximo esquileo. Así procedió, por ejemplo, con un vecino de Pradillo Ilamado Juan de Velasco, contra el que en 1494 solicitó a los oficiales de la justicia que hiciesen ejecución en sus bienes, porque no le entregó la cantidad de lanas que se había comprometido a venderle $^{36}$. Y pocos años antes habría cerrado un acuerdo semejante con Pedro Ruiz de Lezana, el mozo, vecino de Robres, a quien en noviembre de 1490 exigió que le entregase cierta cantidad de lana que le adeudaba ${ }^{37}$. Nada sabemos con precisión sobre el tipo de lana del que se trataba en cada caso, aunque es probable que en el de Juan de Velasco fuese "estremeña"y en el de Pedro Ruiz de Lezana "churra". De cualquier manera tenemos constancia de que Juan de Fuenmayor adquiría las lanas para luego revenderlas a otros mercaderes a los que, significativamente, también concedía aplazamientos de pago. Así se dedu-

34. Vid. GOICOLEA JULIÁN, F. J., "La élite ciudadana...", p. 121. Y "Mercaderes y hombres de negocio..." pp. 960-2.

35. AGS, Cámara-Memoriales, 140-245.

36. AGS, RGS, IX 1494, fol. 74. Comisión al corregidor de Logroño.

37. AGS, RGS, XI 1490, fol. 135. Comisión al corregidor de Logroño. 
ce al menos de la noticia de la demanda que contra él pusieron en 1496 los mercaderes logroñeses Antonio y Sancho de los Arcos, quienes, como ya hemos indicado, le acusaron de haberles vendido ciertas sacas de lana con usura.

Junto con Albelda, otra villa de importancia relativamente menor en la que también operaron tratantes de lanas especializados en el negocio de la reventa fue Cornago, donde los que hasta el momento hemos podido identificar fueron judíos. Entre ellos cabe destacar en primer lugar a Salomon Levi, quien hacia 1485 concertó una singular operación de compra de lanas, al llegar a un acuerdo con el concejo de Cornago por virtud del cual se comprometió a quedarse con todas las lanas que se obtuviesen del esquileo de los ganados de los vecinos de la villa y las aldeas de su Tierra, fuesen muchas o pocas, por el precio fijo de 200 mrs. por arroba. El motivo por el que se concertó un contrato con tan inusuales condiciones estribaba en que el concejo de Cornago necesitaba urgentemente dinero para continuar con el pleito que entonces seguía contra su señor, Juan de Luna ${ }^{38}$, y el referido Salomon Levi se mostraría dispuesto a proporcionárselo. Las razones por las que éste se avino a la operación fueron, por su parte, de carácter eminentemente especulativo, pues sabemos que, antes incluso de haber recibido las lanas, concertó su reventa a unos mercaderes burgaleses. Pero fue una decisión muy arriesgada porque, Ilegada la hora de la entrega de la mercancía, los vecinos de Cornago no quisieron cumplir con lo acordado en el contrato, por razones que desconocemos, y como consecuencia Salomon Levi incurrió en grandes pérdidas, probablemente porque debió compensar a los mercaderes burgaleses por no poderles entregar la lana que se había obligado a venderles, o quizás porque, para cumplir con el compromiso adquirido con ellos, la debió adquirir en otras partes a unos precios sensiblemente más altos que los concertados con el concejo de Cornago ${ }^{39}$.

Salomon Levi no fue el único judío avecindado en Cornago que se interesó por el trato con lanas. Así, nos consta, por ejemplo, que hacia 1492 Juan de Valladolid, mercader de Burgos, compró cierto número de sacas de lana en la feria de Medina de dos judíos vecinos de esta villa riojana por importe de 120.000 mrs., que les abonó, si bien cuando acudió a recibir la mercancía se encontró con que los vendedores habían huido a la ciudad navarra de Corella ${ }^{40}$.

38. Sobre los pormenores de este pleito Vid. DIAGO HERNANDO, M., Estructuras de poder en Soria a fines de la Edad Media, Junta de Castilla y León, Valladolid, 1993, pp. 127 y ss. Y "Los conflictos antiseñoriales en la Rioja en las décadas previas al estallido de la guerra de las Comunidades", Berceo, 152 (2007), pp. 69-71.

39. AGS, RGS, IX-1490, fol. 180. Comisión a Rodrigo Morales, vecino de Soria, para que conozca sobre la denuncia presentada por Simuel Abenamias, vecino de Soria, en nombre de Salomon Levi, vecino que había sido de Cornago, quien había incurrido en grandes pérdidas en una operación de compra de lanas concertada hacía unos cinco años.

40. AGS, RGS, III-1492, fol. 407. 
Y, unos cuantos años antes, en 1489, otro judío vecino de Cornago, David ChiCo, fue denunciado por Lope y Diego de San Vítores, mercaderes vecinos de Burgos, quienes manifestaron que se había obligado a entregarles 200 arrobas de lana fina merina blanca en la villa de San Pedro Manrique, y, ante la imposibilidad de cumplir con este compromiso y de atender al pago de otras muchas deudas que tenía contraídas con otros acreedores, había optado por huir también al reino de Navarra ${ }^{41}$. Se deduce, por tanto, que en este caso los burgaleses le habrían proporcionado al judío cierto capital para que él lo pudiese emplear en compras de lanas a pequeños propietarios de la sierra soriana, del entorno de la villa de San Pedro Manrique, de la que era señor el duque de Nájera. Y por ello cabe presumir que se tratase de un simple regatón de muy limitados recursos financieros.

Los judíos de Cornago sobre los que hemos encontrado referencias en la documentación, y más en concreto en el Registro General del Sello, practicaron la reventa a mercaderes burgaleses, aunque no parece probable que todas las lanas que les revendieron fuesen "estremeñas", que eran las preferidas por éstos para destinarlas a la exportación, por ser las más demandadas en los mercados exteriores, en particular en el flamenco. Pero, dado el carácter en extremo escueto de las informaciones reunidas, no podemos hacer afirmaciones categóricas al respecto, ni entrar a precisar los motivos por los que los mercaderes burgaleses pudieron interesarse por la adquisición en cantidades significativas de lanas churras o riberiegas en la región riojana.

Siguiendo con la identificación de los lugares de segundo rango de la red urbana riojana desde lo que operaron mercaderes laneros, resulta obligada la mención a la villa de Enciso, donde arraigó una importante manufactura pañera que se mantuvo vigorosa a lo largo de los siglos XVI y XVII. No vamos a referirnos aquí a dicha actividad, ni a las vías a las que recurrieron los pañeros para proveerse de materia prima, puesto que las fuentes documentales de fines del siglo XV y comienzos del siglo XVI guardan absoluto silencio al respecto, no sabemos si porque la fábrica de paños todavía no había alcanzado suficiente desarrollo o por otros motivos. Por el contrario, nos limitaremos a Ilamar la atención sobre la presencia por estas fechas en esta villa de individuos que desarrollaron una destacada actividad en el trato de lanas. Es el caso de Diego Jiménez de Enciso, ya fallecido en el año 1520, de quien varios testigos manifestaron que en vida había sido mercader "y trataba en comprar lanas y hacer sacas", por lo que cuando murió "dejó a sus hijos lo más de su hacienda en trato de lanas y sacas". Tras su muerte su viuda puso al frente del negocio, para que lo regentase en su nombre y en el de sus hijos menores de edad, a su cuñado, Juan de Enciso, hermano de su difunto marido. Pero éste no llevó a cabo una gestión

41. AGS, RGS, V-1489, fol. 153. Provisión dirigida a Diego Ramírez, Garcí Pérez y Fernán Calvo, alcaldes de Cornago. 
muy afortunada del mismo, pues, entre otras operaciones, realizó en el año 1520 una de compra de 1.270 arrobas de lana churra a un vecino de Alfaro llamado Rodrigo Mangado por un precio de 380 mrs. por arroba, que se juzgó excesivamente alto para una partida de lana de ganado churro y "de la ribera", que no era fino sino "grosero" ${ }^{42}$. Los pormenores de esta operación, que nos resultan bastante bien conocidos gracias a la documentación generada por el trámite del pleito que después se siguió en relación a la misma en la ChanciIlería de Valladolid, nos demuestran que a fines de la Edad Media residían en la Rioja Baja, y más en concreto en Alfaro, algunos destacados señores de ganados, que reunían rebaños de más de mil cabezas, pero que no practicaban la trashumancia, y como consecuencia ponían a la venta vellones que se cotizaban en el mercado a unos precios sensiblemente inferiores a los pagados por las lanas "estremeñas", es decir, las obtenidas del esquileo de los ganados trashumantes. El tipo de ganado del que eran propietarios es calificado en las declaraciones de testigos como "grosero", "churro" y "de la ribera" , y, en el caso concreto de Rodrigo Mangado, nos consta que era llevado a pastar durante cierta parte del año al reino de Navarra. Estas referencias constantes a la "ribera", que en este contexto concreto no cabe duda que quiere decir "ribera del Ebro", explican que con frecuencia este tipo de ganado, así como las lanas que producía, sean identificados en las fuentes con el nombre de "riberiegos". Pero, dejando a un lado la cuestión de las denominaciones, lo que interesa resaltar es que existía en esta comarca un tipo de ganadero que podía poner en el mercado cantidades relativamente importantes de lanas por ejercicio, y que estas lanas se cotizaban regularmente a precios bastante más bajos que las del ganado trashumante. No todas, por otra parte, alcanzaban una idéntica cotización, sino que, por el contrario, de las declaraciones de diversos testigos, y de otros varios indicios, se puede deducir que dentro del ganado de raza churra que era mantenido en la "ribera" existían notables diferencias que se traducían en diversos grados de finura. Es lo que, en concreto, se deduce de las declaraciones de varios testigos que manifestaron que Rodrigo Mangado había entregado junto con las lanas obtenidas del esquileo de sus propìos rebaños, "mucha lana churra y allegadiza, de las primicias de Alfaro y Aldeanueva y otras partes de la Ribera, que es lana gruesa, que no valía con mucho tantos mrs. como la lana de Rodrigo Mangado". El hecho, por otra parte, de que Juan de Enciso se mostrase dispuesto a pagarle a este ganadero alfareño el elevado precio de $380 \mathrm{mrs}$. por arroba sugiere que, en determinadas circunstancias de carestía, cuando la demanda de lanas superase a la oferta, la lana churra puesta a la venta por determinados grandes propietarios "riberiegos" podía alcanzar cotizaciones próximas a las de la lana "estremeña". Todo dependería de las características concretas del rebaño que proporcionase la lana.

42. AChV, P.C. Pérez Alonso, F. C. 165-1. 
Aclarado este punto se nos plantea, no obstante, la duda de cuál era el destino que tratantes como Juan de Enciso o su hermano Diego Jiménez de Enciso, pretendían dar a estas partidas de lana adquiridas a ganaderos riberiegos, propietarios de rebaños de más de mil cabezas, por las que Ilegaban a pagar precios relativamente altos. No hay que descartar que en ocasiones su objetivo final fuese exportarlas, tratando de presentarlas, de forma más o menos camuflada, como lanas finas. Pero también es posible que las destinasen exclusivamente al aprovisionamiento de la manufactura pañera castellana, y más en concreto de la camerana y riojana. La falta de referencias concretas en la documentación hasta ahora consultada nos impide por el momento determinarlo.

Los mercaderes riojanos que trataron con lanas churras no se limitaron por otra parte a adquirirlas directamente de los ganaderos productores, sino que nos consta que algunos recurrieron también a comprarlas a otros intermediarios que operaban fuera de la región riojana. Un testimonio muy interesante a este respecto nos lo proporciona Pedro de Ocio, mercader perteneciente a una de las principales familias de hombres de negocios de Santo Domingo de la Calzada a principios del siglo XVI, a la que nos referiremos en más de una ocasión a lo largo del presente trabajo por razón de la diversidad de sus actividades. Sabemos que este individuo llegó a constituir una compañía dedicada al trato de lanas con su paisano Pedro González de Pedroso, y que, entre las operaciones realizadas en nombre de dicha compañía, figura una de compra de 4.000 lanas, concertada con un intermediario vecino de la villa soriana de Yanguas Ilamado Antón Sánchez. Había entrado en contacto con este último Diego de Anguiano, vecino de Santo Domingo de la Calzada, que servía como factor a la referida compañía, quien le abonó en concepto de señal la cantidad de 40 ducados, a cambio de lo cual Antón Sánchez de Yanguas se obligó a entregar 4.000 lanas "churras y estremeñas", con la condición de que, si no lo hacía, debería devolver los referidos 40 ducados, más otros 40 en concepto de penalización, y 6 mrs. por cada lana que dejase de entregar por debajo de las 4.000. Finalmente, sin embargo, el intermediario yangüés no fue capaz al parecer de reunir las 4.000 lanas, pues se le acusó de haber entregado una cantidad inferior a la comprometida, y que además se componía exclusivamente de lanas churras, que, por otra parte, no eran de muy buena calidad, dado que muchas estaban "deslomadas y desfaldadas", por lo que ambas partes terminaron litigando en la Chancillería de Valladolid, que expidió la ejecutoria que puso punto final al pleito en diciembre de $1518^{43}$. Sabemos, por otra parte, que la mayoría de las lanas churras que el yangüés Antón Sánchez entregó a la compañía de Pedro de Ocio las había adquirido a campesinos de aldeas de la Tierra de Soria. A este respecto conviene recordar que durante los siglos XVI y XVII los propietarios de

43. AChV, RE, 333-40. Ejecutoria de 22-XII-1518. 
ganados churros de la Tierra de Soria proporcionaron una gran cantidad de lanas a los fabricantes pañeros de las villas cameranas, que las adquirieron en algunos casos a través de intermediarios sorianos y en otros a través de tratantes cameranos que se desplazaban a Soria para negociar directamente con los ganaderos ${ }^{44}$. No consideramos improbable, por tanto, que Pedro de Ocio recurriese a intermediarios como el yangüés Antón Sánchez para evitar la laboriosa e ingrata tarea de entrar en contacto con un gran número de modestos campesinos para comprarles pequeñas cantidades de lanas, a fin de hacerse con partidas de cierta envergadura de lanas churras, que luego pudiese proceder a revender a fabricantes pañeros del entorno camerano. Si, además, parte de estas lanas churras, las de mayor calidad, las destinaba a la exportación junto con las "estremeñas", con las que también nos consta que trataba, es algo que la documentación consultada no nos ha permitido esclarecer.

\section{El comercio de paños}

Junto con el comercio de lanas, el de paños fue uno de los que mayor desarrollo alcanzó en el territorio riojano en la época que estamos analizando, dándose la circunstancia de que muchos de los mercaderes que alcanzaron un notable protagonismo en el primero lo tuvieron también en el segundo. Los paños con los que se negoció fueron, sin embargo, de muy diferentes características, precio y, sobre todo, procedencia, lo cual dificulta bastante la tarea de proporcionar una visión global sobre las carácterísticas de este trato, que, por otra parte, sólo conocemos de forma muy parcial, porque la documentación que se ha conservado es escasa, de carácter fragmentario, y, además, todavía no ha sido explotada de forma sistemática por los investigadores.

Teniendo en cuenta, pues, que el cuadro que estamos en condiciones de ofrecer ha de ser considerado necesariamente como provisional, cabe establecer en primer lugar una distinción básica entre el negocio de la distribución de paños de elevada calidad, que en una proporción importante eran de importación, y el de venta de paños de producción local, procedentes de los talleres de las villas cameranas, que experimentaron un extraordinario desarrollo a partir de la segunda mitad del siglo $\mathrm{XV}$, hasta consolidarse como unos de los principales centros de producción pañera del reino de Castilla.

La distribución de los tejidos de mayor calidad, entre los que, junto a los paños de lana, ocupaban un lugar prominente los tejidos de seda, estuvo en manos de los mercaderes de mayor relieve, que en la mayor parte de los casos pueden ser también identificados como dinámicos tratantes laneros. Éstos tuvieron entre sus clientes a miembros de la alta y media nobleza de la región rioja-

44. Para más detalles al respecto Vid. DIAGO HERNANDO, M., "El papel de la lana en las relaciones económicas entre Soria y las villas pañeras cameranas...". 
na, o de lugares muy próximos a ella, a los que con frecuencia vendieron a crédito sus productos, tropezando en bastantes casos después con graves dificultades para cobrar las cantidades acordadas, por ser éstos individuos poderosos y señores de vasallos, que lograban con relativa facilidad escapar a la acción de la justicia del rey, y por ello solían mostrarse muy remisos a pagar sus deudas. Los testimonios que proporciona la documentación sobre este fenómeno son relativamente numerosos. Nos limitaremos a hacer referencia a unos cuantos, para al mismo tiempo aportar datos que nos permitan conocer la identidad de algunos de los principales comerciantes riojanos que negociaron con tejidos de lujo. Así, en primer lugar, tenemos que en 1503 Sebastián de Bedoya, mercader vecino de Calahorra, declaró que él había vendido a crédito a Juan de Mendoza, señor de Lodosa, en el reino de Navarra, paños, sedas y otras mercancías, y había realizado otros diversos pagos en su nombre, por todo lo cual le adeudaba importantes cuantías de dinero, que, no obstante, no precisó a cuánto ascendían ${ }^{45}$. Por estas mismas fechas, García de Soria, mercader vecino de Logroño, declaró que había vendido a crédito paños y sedas al duque de Nájera, y le había efectuado algunos préstamos de dinero, a raíz de lo cual el duque había presentado como fiadores suyos a los concejos de Navarrete y Ocón, villas de su señorío. El poderoso duque no cumplió con el pago de las cantidades comprometidas en los plazos establecidos, y por ello García de Soria acudió ante los concejos de estas dos villas riojanas para exigirles que le pagasen en lugar de su señor, pues habían quedado obligados como sus fiadores. Pero las autoridades concejiles respondieron poniendo excusas para no pagar, y por ello finalmente en 1503 García de Soria tuvo que recurrir ante la monarquia para que se le hiciese justicia ${ }^{46}$. No debió ser éste, por otra parte, el único caso de impago por parte del duque de Nájera que ocasionó notable perjuicio a mercaderes riojanos, especializados en la venta a crédito de productos de consumo suntuario. Así nos lo sugiere, por ejemplo, un documento del año 1502, que recoge la denuncia de Juan de Encinas, mercader vecino de Santo Domingo de la Calzada, que acusó a Martin de Gante, criado del duque, de adeudarle la astronómica cifra de 689.130 mrs. por virtud de diversos contratos ${ }^{47}$. Por supuesto, a partir de esta escueta noticia no cabe concluir que el origen de esta abultada deuda estuviese en ventas a crédito de mercancías, y más en particular de tejidos, efectuadas por el mercader calceatense al propio duque de Nájera. Pero no resulta del todo improbable.

45. AGS, RGS, XII-1503.

46. AGS, Cámara-Personas, leg. 27. Memorial del bachiller Villegas, en nombre de García de Soria, vecino de Logroño. García de Soria otorgó carta de procuración en favor del bachiller Villegas en Logroño, 12-VI-1503.

47. AGS, RGS, IX-1502. Comisión al corregidor de Santo Domingo, a petición de Juan de Encinas. 
En fechas más avanzadas del siglo XVI otros varios mercaderes vecinos de Logroño denunciaron a otros señores de vasallos de la nobleza media riojana a los que habían vendido a crédito paños, sedas y otras mercancías, por no haberles pagado las cantidades comprometidas en los plazos establecidos en los contratos de obligación. Así lo hicieron en 1517 Pedro Rodriguez y Diego Rodriguez, su hijo, quienes denunciaron que Juan de Lezana, señor de Robres, y algunos de sus vasallos, les adeudaban por este concepto $23.047 \mathrm{mrs}{ }^{48}$. Al año siguiente Juan de Gaona y Diego de Villoslada, reclamaron con este mismo argumento a Francisco de Porras, señor de Agoncillo, la suma todavía mucho más elevada de 180.000 mrs. ${ }^{49}$. Y, pocos años más tarde, en 1520, tocó el turno a Diego y Antonio de Yanguas, dos de los más destacados mercaderes logroñeses por estas fechas, de denunciar a algunos señores de vasallos de la comarca porque les adeudaban dinero por el valor de mercancías que les habían vendido, y, "por ser caballeros y personas principales", no les querían pagar ${ }^{50}$. En esta ocasión no hicieron más precisiones sobre la identidad de los morosos, pero unos pocos años después, en 1523, el propio Antonio de Yanguas fue más preciso en sus denuncias, al acusar a Don Álvaro de Luna, señor de Cornago y Jubera, de adeudarle 50.000 mrs. por el valor de diversas mercancías que había sacado de su tienda, y que debería haberle abonado en plazos hacía ya tiempo cumplidos ${ }^{51}$.

Por fin también interesa dejar constancia de que otro destacado mercader logroñés, Hernando de Soria, cuñado del ya mencionado Diego de Yanguas, denunció en 1520 que Ruy Díaz de Fuenmayor, vecino de Arnedo, mayordomo del conde de Nieva, y Cristóbal de Alfaro, le adeudaban por virtud de un contrato de obligación la elevada cuantía de 300.000 mrs., que se negaban a abonarle pese a que hacía ya tiempo que había vencido el plazo de pago ${ }^{52}$. Nada sabemos sobre cuál era el origen de la deuda, pero, teniendo en cuenta que uno de los deudores era mayordomo del conde de Nieva, no consideramos improbable que estuviese en alguna operación de venta a crédito de tejidos y otras mercancías de lujo para el consumo de la propia casa condal.

A partir de estas noticias, pese a su carácter en extremo puntual y en ocasiones también demasiado vago, podemos deducir, por tanto, que los mercaderes especializados en la venta de tejidos de calidad, destinados al consumo de

48. AGS, RGS, VIII-1517.

49. AGS, RGS, X-1518. Comisión al corregidor de Calahorra.

50. AGS, RGS, VI-1520. Comisión al corregidor de Logroño.

51. AGS, RGS, IV-1523. Provisión a Don Álvaro de Luna, señor de Cornago y Jubera.

52. AGS, RGS, VII-1520. Provisión a los alcaldes ordinarios de Arnedo. Para conocer con más detalle el perfil del mercader Hernando de Soria Vid. GOICOLEA JULIÁN, F. J., "La élite ciudadana de Logroño en el tránsito de la Edad Media a la Moderna: Las familias Soria y Yanguas", Berceo, 150 (2006), pp. 115-141. En pp. 133-141 transcribe su testamento del año 1532. 
los sectores más encumbrados de la sociedad riojana, estuvieron repartidos por los principales núcleos urbanos de la región, aunque aparentemente fue en Logroño donde en mayor medida se concentraron. Entre sus clientes no cabe duda de que ocuparon un lugar principal los miembros de la alta y media nobleza, aunque, a juzgar por las dificultades con que tropezaron en bastantes ocasiones para cobrarles, habría que cuestionarse si el trato con ellos fue un negocio rentable. Con los elementos de información de los que de momento disponemos no lo podemos saber. En cualquier caso es seguro que su clientela estuvo bastante más diversificada. Así nos lo ponen de manifiesto, por ejemplo, los contratos concertados por el ya mencionado Antonio de Yanguas, mercader vecino de Logroño, en el año 1535 que ha dado a conocer recientemente F.J. Goicolea, los cuales ponen de manifiesto que los individuos a los que éste vendió paños, bien de importación o bien procedentes de otros centros pañeros castellanos como Segovia o Palencia, en la mayor parte de los casos no ocupaban posiciones muy destacadas en el terreno sociopolítico, contándose entre ellos incluso algunos artesanos ${ }^{53}$. Y otro tanto cabría decir de los clientes que compraron paños en este mismo ejercicio a otros mercaderes vecinos de Logroño que concertaron escrituras de obligación ante el escribano Cristóbal Rodríguez, recientemente identificados por este mismo autor ${ }^{54}$.

Poco podemos decir, por otra parte, sobre cómo se organizaba este trato. Las noticias recogidas demuestran que fue habitual la venta a crédito del producto a los consumidores, y a veces quizás también a tenderos minoristas, ambulantes ${ }^{55}$ o con tienda estable, que, de momento, no hemos logrado identificar. Mucho menos sabemos, sin embargo, sobre los procedimientos de adquisición de la mercancía. Por lo que toca a los paños de importación, cabe la posibilidad de que fuesen adquiridos a trueque de lanas, aunque también nos consta que mercaderes de Logroño invertían importantes cantidades de dinero en la compra de paños en las ferias de Medina del Campo, por un lado, y en la ciudad de Bilbao, importante puerto de entrada de mercancías de importación, por otra ${ }^{56}$. También

53. GOICOLEA JULIÁN, F. J., "La élite ciudadana.. " pp. 111-121.

54. GOICOLEA JULIÁN, F. J., "Mercaderes y hombres de negocio...", pp. 953-9.

55. Un interesante ejemplo de mercader minorista ambulante lo encontramos documentado en Santo Domingo de la Calzada a principios del siglo XVI. Se trata de Juan Restán, quien, según su propia declaración, solía llevar dos o tres "arcas de mercaduría" para vender por los lugares del entorno, entre ellos la villa de Treviño, donde en una ocasión los oficiales de la justicia local le llegaron a apresar, acusándole de vender objetos de plata falsos. Además de plata, también llevaba en sus arcas cuchillería, lienzos, y otras mercancías. Noticia sobre la denuncia presentada por Juan Restán contra las justicias de Treviño en AGS, RGS, VIII-1522.

56. Vid. GOICOLEA JULIÁN, F. J., "Mercaderes y hombres de negocio...", pp. 963-4. Sobre la importancia creciente de Bilbao como centro de redistribución de mercancías de importación, en especial a partir del siglo XVI, aporta algunas noticias PRIOTTI, J. Ph., Bilbao y sus mercaderes en el siglo XVI. Génesis de un crecimiento, Diputación Foral de Vizcaya, Bilbao, 2005. 
en las ferias de Medina del Campo, Villalón y Medina de Ríoseco debieron adquirir los mercaderes riojanos la mayor parte de los paños producidos en los grandes centros pañeros castellanos, pues las mismas fueron durante la segunda mitad del siglo XV y la primera mitad del siglo XVI los principales centros de comercialización de la producción pañera castellana. No obstante, habría que profundizar en el análisis de la documentación para disponer de noticias más detalladas al respecto, y conocer mejor los mecanismos de financiación del comercio pañero, en el que el crédito desempeñó un papel fundamental. A este respecto cabe adelantar que en los protocolos notariales de Medina del Campo de las primeras décadas del siglo XVI abundan los contratos de obligación en los que mercaderes de las más diversas procedencias se obligaban a pagar a otros mercaderes en varios plazos cuantías de dinero que les adeudaban por el valor de mercancías que les habían comprado. Lamentablemente en la mayor parte de los contratos no se hace constar de qué mercancías en concreto se trataba, pero no parece improbable que entre ellas figurasen en muchos casos los paños. Esta abundante información está todavía pendiente de ser analizada de forma sistemática, pero en unas primeras aproximaciones hemos podido comprobar que entre los compradores de mercancías que firmaban contratos de obligación para pagarlas a plazos hubo mercaderes riojanos.

En el territorio de la actual comunidad de La Rioja tuvo lugar, por otra parte, desde la segunda mitad del siglo XV un importante proceso de desarrollo de la actividad de fabricación de paños, en el que tomaron parte activa mercaderes, que, convertidos en auténticos empresarios, supervisaron todas las fases del proceso productivo, proporcionando a los artesanos la materia prima necesaria, y finalmente se hicieron cargo de la comercialización del producto acabado, o incluso semiacabado en determinados casos. No es mucho lo que de momento sabemos con certeza sobre la identidad de estos mercaderes-empresarios y su papel en las primeras fases de desarrollo de la manufactura pañera en tierras de Rioja y Cameros. Un rasgo peculiar de esta manufactura es que arraigó sobre todo en el ámbito rural, y muy en particular en las comarcas serranas, que se especializaron en la producción de tejidos de baja calidad, pero que se destinaban masivamente a la exportación a otras regiones de la Corona de Castilla, donde eran demandados por los sectores populares. Pero no sabemos mucho sobre las conexiones que pudo haber entre los mercaderes de los principales núcleos urbanos de la región, y los lugares de la sierra donde se elaboraban los paños.

No podemos entrar aquí a tratar de clarificar esta compleja cuestión, que exige que se le dedique todo un trabajo monográfico. Por el momento nos limitaremos a recordar que en 1494 varios destacados mercaderes vecinos de Logroño fueron denunciados por el incumplimiento de una pragmática recientemente publicada por los Reyes Católicos que prohibía la venta de paños sin tundir. Se trataba en concreto de Diego de Villoslada, Diego de Haro, Alonso el Roxo, Juan de Gaona, Esperandeo, Juan Mercadero, Juan de la Torre, Alonso Moreno y Antonio de Yanguas, quienes fueron acusados por un tundidor vecino 
de Logroño Ilamado Pedro González de haber vendido paños sin tundir ${ }^{57}$. A partir de esta escueta noticia resulta imposible determinar si todos estos mercaderes tenían intereses en la actividad de la fabricación de paños, pues no se puede excluir que los que habían vendido sin tundir los hubiesen adquirido a fabricantes o incluso a otros mercaderes. Pero no deja de resultar bastante sintomático que vendiesen tejidos semi-acabados, pues a nuestro entender sugiere una notable cercanía a los procesos de producción. Y, en cualquier caso, esta noticia demuestra que los mercaderes logroñeses no se limitaban a tratar con paños de importación de elevada calidad y precio, sino que también lo hacían con los de producción local, los Ilamados "de la tierra", y no sólo para atender la demanda local, puesto que en el caso de varios de los denunciados en 1494 se hizo constar que habían vendido paños a forasteros que se los habían llevado para tundirlos fuera de Logroño, y suponemos que fuera también de la propia región riojana.

Por lo demás, fuera de Logroño, también disponemos de algunos indicios que sugieren que en otros núcleos urbanos de la Rioja pudo alcanzar cierto desarrollo la figura del mercader-empresario interesado por el fomento de la producción pañera. Es el caso de Santo Domingo de la Calzada, donde un miembro de la polifacética familia de los Ocio, Juan Sánchez de Ocio, llegó a un acuerdo hacia 1485 con el cabildo de la catedral para construir un tirador en uno de sus solares, y donde estaban avecindados algunos otros individuos que los documentos identifican como mercaderes "de facer paños", como Diego Sánchez, originario de la villa camerana de Lumbreras $^{58}$.

El desarrollo de la actividad manufacturera en las comarcas serranas de la Rioja estimuló por otra parte el comercio de las materias primas necesarias para dicha manufactura. Y entre ellas cabría destacar por su importancia, después de la lana, los productos colorantes, entre los cuales en esta época uno de los principales fue el pastel. Resulta bien sabido, gracias a los trabajos de Hilario Casado Alonso, que algunas casas mercantiles de Burgos, como la de los Bernuy, desplegaron una intensa actividad en el comercio de este producto colorante, que les Ilevó incluso a establecerse con carácter permanente en la ciudad francesa de Toulouse ${ }^{59}$. Y burgaleses fueron, en efecto, los principales proveedores de colorantes para los pañeros que trabajaron en las sierras del Sistema Ibérico en

57. AGS, Cámara-Pueblos, leg. 10, fol. 198. Logroño, 15-XI-1494. Y fol. 199, Carta de poder otorgada en Logroño, 29-XI-1494, por Diego de Villoslada, Juan de Gaona, Alonso el Rojo y Antón de Yanguas, mercaderes, y Esperandeo, mercader, por sí y en nombre de los demás mercaderes de Logroño, "como su mayordomo", a Juan de Huete para recurrir unas sentencias dadas contra ellos por el bachiller García Fernández de Jaén, teniente de corregidor de Logroño.

58. GOICOLEA JULIÁN, F. J., "Mercaderes y hombres de negocio...", p. 953.

59. CASADO ALONSO, H., "El comercio del pastel: Datos para una geografía de la industria pañera española en el siglo XVI", Revista de Historia Económica, VIII, n. 3 (1990), pp. 523-48. 
su sector riojano a fines del siglo XV y principios del siglo XVI. De igual modo también está constatada la presencia como vendedores de colorantes en esta región de mercaderes franceses, aunque no estimamos improbable que pudiesen ser de ascendencia burgalesa. Una buena prueba de dicha presencia nos la proporciona una petición presentada ante los gobernadores en 1521 por un mercader logroñés Ilamado Pedro de Angulo, quien solicitó que se le compensase por el valor de ciertas sacas de lana que le habían sido tomadas por los ejércitos franceses, transfiriéndole el derecho a cobrar ciertas cuantías de dinero que se adeudaban a súbditos del rey de Francia por vecinos de Valdezcaray y Torrecilla de Cameros $^{60}$. Nada se indica en el documento sobre quiénes eran estos súbditos ni sobre el origen de las deudas que tenían contraídas con ellos los vecinos de estas dos villas riojanas. Pero, teniendo en cuenta que se trataba de dos de los principales centros de producción pañera de la región, la explicación más razonable es que les hubiesen comprado a crédito alguna carga de pastel.

El negocio de la venta de pastel a fabricantes pañeros no fue, en cualquier caso, controlado en su integridad por mercaderes foráneos, bien burgaleses o bien franceses. También nos consta que desempeñaron cierto papel en el mismo los propios mercaderes riojanos. Así, en primer lugar, cabe destacar que Juan Sánchez de Ocio y su hijo Sebastián, vecinos de Santo Domingo de la Calzada, Ilegaron a desplazarse a la ciudad francesa de Toulouse en 1487 para comprar este producto colorante, entre otras varias mercancías ${ }^{61}$. Por su parte los mercaderes logroñeses Pedro de Soria y Pedro de Villoslada nos consta que con anterioridad a 1492 habían realizado diversas operaciones de venta a crédito de pastel a vecinos de Ezcaray, Ojacastro, Bañares y Ortigosa ${ }^{62}$. Y de igual manera, otros documentos nos proporcionan indicios de que algunos vecinos de las propias villas pañeras cameranas participaron de forma activa en este trato. En este sentido resulta reveladora la denuncia presentada en 1508 por Pedro Sánchez de Ocenilla, mercader vecino de Soria, contra García de Larios, vecino de Torrecilla de Cameros, a quien acusó de haber vendido sin licencia suya una carga de pastel que le había dejado "en guardas" un criado suyo ${ }^{63}$. No resulta fácil determinar los motivos que pudieron llevar al referido criado del mercader soriano a dejar depositada en poder de García de Larios la carga de pastel. Pero esta noticia nos pone de manifiesto que la negociación con este colorante no se limitaba a las transacciones directas entre los grandes mercade-

60. AGS, RGS, IV-1522. Provisión al corregidor de Logroño, a petición de Pedro de Angulo, vecino de Logroño.

61. Vid. MOYA VAlGaÑón, J. G., Documentos para la Historia del Arte del Archivo Catedral de Santo Domingo de la Calzada, 1443-1563, Logroño, 1986, doc. nº. 63, p. 62.

62. AGS, RGS, II 1492, fol. 336. Iniciativa a los alcaldes de Ezcaray, Ojacastro, Bañares y Ortigosa.

63. AGS, RGS, IV-1508. Provisión dirigida a los oficiales de la justicia de Torrecilla de Cameros. 
res proveedores y los fabricantes pañeros, sino que con frecuencia el producto pasaba por las manos de varios intermediarios. Y para ayudar a conocer mejor el perfil de uno de éstos, el mencionado García de Larios, consideramos pertinente recordar que varias décadas más tarde, a mediados del siglo XVI, otro individuo con este mismo nombre, que debía ser descendiente suyo, junto con su hermano Pedro Larios, pasaron a instalarse en la ciudad de Soria, donde desarrollaron una intensa actividad en el comercio de lanas, preferentemente churras, y en la fabricación de paños, que promovieron en calidad de mercaderes-empresarios, poniendo a su servicio a una abundante mano de obra que en parte residía en las comarcas serranas de los Cameros, donde con frecuencia se realizaban por cuenta suya las labores del hilado ${ }^{64}$.

\section{El negocio del abastecimiento en productos de consumo alimenticio}

Entre las numerosas ramas de la actividad mercantil por las que mostraron interés las principales familias de mercaderes residentes en las ciudades riojanas a fines de la Edad Media no podemos dejar de mencionar la del abastecimiento de productos alimenticios de primera necesidad a la población urbana. Se trataba de una actividad férreamente reglamentada por las autoridades de gobierno local, para las que el poder garantizar un regular abastecimiento de este tipo de productos al conjunto de los vecinos en condiciones asequibles era un objetivo básico de su acción de gobierno, que, de no alcanzarse, podía amenazar seriamente su posición, dado que la existencia de problemas de desabastecimiento en amplios sectores de la población podía desencadenar graves disturbios. Como consecuencia, la dedicación a esta rama del comercio exigía el mantenimiento de estrechos y permanentes contactos con las autoridades concejiles, y, desde este punto de vista, puede afirmarse que estaba en mayor grado "politizada", pues para poder invertir en ella con provecho resultaba con frecuencia preciso contar con contactos en las instituciones de gobierno local, que disponían en este terreno de un amplio margen discrecional, y no siempre atendían a criterios de carácter estrictamente económico a la hora de tomar sus decisiones.

Probablemente la actividad de abastecimiento en productos alimenticios de consumo básico que más atrajo a los mercaderes en las ciudades castellanas del período bajomedieval y moderno por las posibilidades que ofrecía para alcanzar elevados beneficios fue la del abastecimiento de carnicerías,

64. Algunos datos sobre la actividad de los hermanos Larios en Soria a mediados del siglo XVI en DIAGO HERNANDO, M., "El comercio de las lanas churras...". Sobre la importancia de la figura de los mercaderes-empresarios en la manufactura pañera soriana del siglo XVI, Vid. DIAGO HERNANDO, M., "Desarrollo de la industria pañera en Soria en el siglo XVI", Celtiberia, 87-88 (1994), pp. 105-30. 
que en la mayor parte de ellas se realizó en esta época en régimen de concesión del monopolio de venta de carne por parte de la autoridad concejil al mejor postor tras pública subasta ${ }^{65}$. Así se procedió en concreto en las principales ciudades riojanas. Y, aunque los datos de que disponemos sobre la identidad de las personas en quienes fueron rematadas sus carnicerías en el período que estamos tomando en consideración en el presente trabajo son, como siempre, sumamente fragmentarios, resultan suficientes para comprobar que los mismos mercaderes que despuntaron en el comercio de la lana o de los tejidos en estas ciudades, invirtieron con frecuencia también en este negocio. Así lo constatamos, por ejemplo, en Santo Domingo de la Calzada, donde uno de los mercaderes más activos de la ciudad a principios del siglo XVI, Pedro de Ocio, de quien conocemos bien su faceta como arrendador de rentas de la monarquía y como tratante de lanas y paños, también mostró interés por hacerse cargo del abastecimiento de carne, incluso en momentos en que, conforme a la legislación vigente, no podía hacerlo por desempeñar un oficio de gobierno local que le inhabilitaba para ello. Así ocurrió en concreto en 1520, cuando fue elegido para desempeñar el puesto de regidor, que era entonces todavía en esta ciudad un oficio de renovación anual. Ello no le impidió, sin embargo, hacer una postura cuando se abrió la subasta para la concesión del abasto de las carnicerías de esta ciudad en ese ejercicio, ofreciendo unas condiciones más favorables que el resto de sus competidores, es decir, básicamente el compromiso de vender la carne a los consumidores a unos precios más bajos que los ofertados por los demás. Por ello, con el argumento de que su oferta era beneficiosa para el conjunto de la ciudad, acudió ante los órganos de gobierno central de la monarquía para solicitar que se le concediese licencia para poder tomar a su cargo el abasto de la carne de Santo Domingo de la Calzada, pese a ser regidor de esta ciudad. Y dichos órganos accedieron sin inconveniente a su solicitud ${ }^{66}$.

También en la ciudad de Logroño algunos de los más destacados mercaderes invirtieron en el negocio de abastecimiento de carne a la población local. Es el caso de Rodrigo de Yanguas, individuo que, en representación del estamento de los ciudadanos, desempeñó un muy activo papel en la vida política logroñesa en los primeros años del siglo $\mathrm{XVI}^{67}$, y formaba parte de una de las

65. Un buen ejemplo ilustrativo de cómo se regulaba el abastecimiento de carne en una ciudad castellana en el siglo XVI en HERNÁNDEZ ESTEVE, E., Noticia del abastecimiento de carne en la ciudad de Burgos (1536-7). Libro Mayor del obligado de las carnicerías, Banco de España, Madrid, 1992.

66. AGS, RGS, VII-1520. Licencia a Pedro de Ocio, regidor de Santo Domingo de la Calzada, para tomar a su cargo el abasto de la carne.

67. GOICOLEA JULIÁN, F. J., El gobierno urbano en la rioja en la época medieval e inicios de la Edad Moderna (s. XIII-mediados del XVI), Instituto de Estudios Riojanos, Logroño, 2004, p. 33. 
familias principales de la élite mercantil local, la de los Yanguas ${ }^{68}$. Sabemos en concreto que en él fue rematada la carnicería de Logroño para el ejercicio anual que se iniciaba en la fiesta de San Juan Bautista del año 1514, con la condición de vender la cuarta de carnero a 16,5 mrs. y la de vaca a 11,5 mrs. Poco después, no obstante, el regidor Lope de Viana, y Juan de Viana, su hermano, para perjudicarle, pues abrigaban hacia él sentimientos de odio y enemistad, llegaron a un acuerdo con un vecino de Alfaro, Rodrigo Mangado, propietario ganadero a quien ya nos hemos referido al tratar del comercio lanero como vendedor de lanas churras, para que se ofreciese al concejo logroñés como abastecedor de la dicha carnicería, comprometiéndose a vender la carne a precios inferiores a los ofertados por Rodrigo de Yanguas. Tal propuesta fue admitida en concejo, y como consecuencia se volvió a rematar de nuevo la carnicería a favor del referido Rodrigo Mangado, desplazando a Rodrigo de Yanguas, que sufrió en consecuencia un grave perjuicio, pues, como denunció, ya había comenzado a realizar importantes inversiones en la compra de reses para cumplir con sus obligaciones de abastecedor, enviando a sus criados a efectuar compras a la comarca de la "ribera del Guadiana", donde presumimos que debía haber una importante oferta de carneros a fines de la primavera, procedentes de las cabañas de ganado trashumante que pasaban los inviernos en las dehesas de la zona ${ }^{69}$.

Por su parte, en Calahorra hemos podido comprobar que uno de los más destacados mercaderes y hombres de negocios de la ciudad en el tránsito del siglo XV al XVI mostró un fuerte interés por el negocio del abastecimiento de carne. Se trata de Sebastián de Bedoya, quien, además de dedicarse a diversas actividades mercantiles y financieras, nos consta que desempeñó durante un tiempo el oficio de dezmero del puerto seco de Calahorra, es decir, que fue el encargado de recaudar los impuestos aduaneros que se cargaban sobre las mercancías que circulaban entre Castilla y Navarra por aquel sector de la frontera. Su interéres por el negocio del abastecimiento de carne está por su parte atestiguado por numerosas noticias dispersas por la documentación de la última década del siglo XV y de las dos primeras del siglo XVI. La primera referencia que nos pone de manifiesto su vinculación con el mismo data de 1497, si bien en aquel año su función no fue la de abastecedor propiamente dicho, sino la de arrendador de la renta del alcabala de la carne, pues fue en calidad de tal que denunció que los clérigos de las iglesias de San Andrés y Santiago habían abierto nuevas carnicerías y no querían pagar dicha renta, alegando exención por razón de su pertenencia al estamento eclesiástico ${ }^{70}$. Más adelante, sabemos que se hizo cargo del abastecimiento de las carnicerías calagurritanas en el año

68. Sobre esta familia Vid. GOICOLEA JULIÁN, F. J., "La élite ciudadana de Logroño...". 69. AGS, RGS, VI-1514. Provisión al corregidor de Logroño.

70. AGS, RGS, IV-1497, fol. 204. 
1508, si bien, al poco de haberle sido rematadas, los regidores aceptaron una nueva postura realizada por otro mercader del que desconocemos el nombre, que ofreció vender la carne a precios más bajos ${ }^{71}$. No fue el único desencuentro que por motivos relacionados con la gestión de las carnicerías tuvo con las autoridades concejiles calagurritanas. Por el contrario, resulta muy revelador a este respecto constatar que pocos años después, en 1515, acudió a la Corte para denunciar, "como uno del pueblo", que en los años 1512 y 1513, habiendo personas que estaban dispuestas a tomar a su cargo el abastecimiento de carne en la ciudad, algunos regidores no habían querido aceptar sus posturas, optando por la solución alternativa de que el propio concejo se hiciese cargo de la gestión de la carnicería. Para ello nombraron a dos diputados, que se debían encargar de comprar los animales necesarios para garantizar el abasto, y atender otras cuestiones relacionadas con éste. Y, según su punto de vista, la gestión de éstos había sido tan desafortunada que, como consecuencia, el concejo había perdido una importante cantidad de dinero, cifrada en torno a los 20.000 mrs., que los regidores pretendían recobrar efectuando un repartimiento entre todos los vecinos $^{72}$. No parece improbable que entre las personas que habían mostrado interés por hacerse cargo del abasto de la carnicería , y a las que los regidores habían rechazado, figurase el propio Sebastián de Bedoya. Y de ahí vendría su interés en denunciar ante las autoridades de gobierno central de la monarquía la mala gestión de las carnicerías que había llevado a incurrir en tan abultadas pérdidas, de las que los ineptos gobernantes luego querían hacer corresponsables a todos los vecinos. Por paradojas del destino, sin embargo, poco tiempo después el propio Sebastián de Bedoya tendría ocasión de experimentar en su propia persona que el negocio del abastecimiento de carne era de por sí arriesgado, y fácilmente podía generar pérdidas. En efecto, nos consta que en 1516 logró, por fin, que el concejo calagurritano le concediese por un año el abastecimiento de las carnicerías, pero no tuvo suerte en su gestión, y pronto comenzó a perder importantes cantidades de dinero, por lo que finalmente se vio forzado a solicitar al concejo la concesión de algún descuento.Al parecer algunos de los oficiales se mostraron dispuestos a acceder a su solicitud, pero otros, por animadversión que sentían hacia su persona, se opusieron frontalmente a conceder lo que solicitaba, de modo que finalmente tuvo que intervenir la monarquía para ordenar al corregidor que se informase y decidiese al respecto ${ }^{73}$.

Todas estas noticias demuestran, por tanto, que el interés de Sebastián de Bedoya por el negocio del abastecimiento de carne fue continuado y persistente,

71. AGS, RGS, III-1509. También en las actas del concejo, en la de la sesión de 28-XII-1508, se hace constar que se dio respuesta a las peticiones de Sebastián de Bedoya para que se le proveyese de remedio por la pérdida de la carnicería.

72. AGS, RGS, XI-1515. Provisión al corregidor de Calahorra.

73. AGS, RGS, VII-1517. 
pese a que, como consecuencia del mismo, se vio abocado a mantener relaciones sumamente tensas con un sector de la sociedad política calagurritana, que desarrolló hacia él una abierta animadversión, que se tradujo en el hecho de que en unas ocasiones presionó para que no se le admitiesen las pujas, y en otras para que no se renegociasen con él las condiciones con las que se le habían rematado las carnicerías. Todo lo cual, al igual que los problemas que hemos comprobado que tuvo que afrontar en Logroño Rodrigo de Yanguas, demuestra que éste era un negocio que podía verse fácilmente afectado por factores de carácter político, que introducían un importante factor de riesgo, aunque en ocasiones podían asegurar también un margen de beneficio mayor del habitual, cuando se conseguía que las autoridades concejiles efectuasen la concesión en condiciones muy favorables.

El interés de destacados representantes de familias de mercaderes por el negocio del abastecimiento de carnicerías también puede constatarse en Nájera, donde, por ejemplo, Alonso González de Belorado se hizo cargo del mismo durante varios $a_{n}{ }^{74}{ }^{74}$ Y, por otro lado, de igual manera está atestiguado en todas las ciudades riojanas el interés de estas mismas familias por otras actividades relacionadas con el abastecimiento de productos alimenticios a la población urbana en régimen de concesiones de monopolio de la venta al por menor efectuadas por las autoridades municipales en pública subasta. Así, por ejemplo, miembros de la familia Moreno, una de las principales del estamento ciudadano de Logroño, tomaron a su cargo en varias ocasiones el abastecimiento de las tiendas de esta ciudad, especializadas en la venta al por menor de aceite y pescado, y lo mismo hicieron en Nájera miembros de la ya mencionada familia de los Belorado, y en Santo Domingo de la Calzada miembros de la también varias veces aludida familia de los $\mathrm{Ocio}^{75}$. De menor entidad parece que fue, por el contrario, el negocio de venta al por menor de vino en las tabernas, por el que, a juzgar por las noticias proporcionadas por Goicolea Julián, se interesaron preferentemente hombres de negocios de perfil algo más modesto, como Juan de Zaldo en Santo Domingo de la Calzada o Juan Ortiz de Bobadilla en Calahorra ${ }^{76}$.

\section{Actividades financieras: El arrendamiento de rentas de la monarquía}

Las ciudades riojanas no se contaban a fines de la Edad Media entre los principales centros financieros de la Corona de Castilla. Para realizar sus transacciones financieras de mayor envergadura sus vecinos solían, por el contrario, trasladarse a otros lugares, de entre los que cabe destacar por su importancia durante la segunda mitad del siglo XV y la primera mitad del siglo XVI las villas de Medina del Campo, Medina de Ríoseco y Villalón, donde se celebraban ferias en las

74. GOICOLEA JULIÁN, F. J., "Mercaderes y hombres de negocio..." p. 949.

75. Íbid. p. 949-50.

76. Íbid. p. 950. 
que, además de intercambiarse mercancías de todo género, se concertaron en un creciente número operaciones de cambio de moneda entre diversas plazas europeas, que en muchos casos no eran más que préstamos enmascarados, a los que se recurría para salvar la prohibición eclesiástica del cobro de interés. La presencia de vecinos de Logroño en las ferias de Medina del Campo para la concertación de este tipo de operaciones fue notable a lo largo del siglo XVI, según atestiguan los protocolos notariales de esta villa vallisoletana. No podemos entrar aquí, sin embargo, a identificar en detalle a estos individuos, ni a determinar el carácter de los negocios financieros que con notable asiduidad realizaron en las referidas ferias de Medina, por tratarse de una tarea muy compleja, que nos llevaría además a sobrepasar el marco cronológico escogido para el presente trabajo. Baste con haber dejado constancia del fenómeno, como llamada de atención para que en el futuro se le puedan dedicar nuevos estudios enfocados a su clarificación. Por el momento aquí nos limitaremos a tratar de otro aspecto de la actividad financiera desarrollada por los hombres de negocios riojanos a fines del siglo XV y comienzos del siglo XVI sobre el que hemos logrado reunir mayor cantidad de información. Nos referimos al arrendamiento y recaudación de rentas pertenecientes a la Real Hacienda.

En este negocio los vecinos de las ciudades riojanas no llegaron, sin embargo, a desempeñar un papel particularmente destacado en esta época, sino que en rigor más bien cabría calificarlo de discreto. Hubo en ellas, en efecto, individuos que se hicieron cargo en calidad de arrendadores mayores de la recaudación de rentas de la monarquía, pero no fueron muchos, y ninguno de ellos se contó entre los principales del reino. Así, las rentas que tomaron a su cargo fueron preferentemente las que se habían de recaudar en el propio ámbito riojano, o, a lo sumo, en comarcas próximas, pero apenas los encontramos como recaudadores en otras regiones de la Corona de Castilla muy alejadas de la Rioja. La única excepción significativa que contradice esta norma viene representada por la figura de Pedro de Monteser, que era originario de Logroño, y llegó a convertirse en un destacado financiero al servicio de la monarquía, que tomó a su cargo la recaudación de muchas y muy diversas rentas a lo largo y ancho de la geografía castellana, incluido el reino de Galicia $^{77}$. Su carrera como financiero la desarrolló, no obstante, cuando ya había abandonado la capital riojana, para establecerse primero en Toledo $^{78}$, y después en Valladolid, donde nos consta que residía en 1516, fecha en la que

77. Algunas referencias de interés sobre la faceta de Pedro de Monteser como financiero al servicio de la monarquía en ALONSO GARCíA, D., El erario del reino. Fiscalidad en Castilla a principios de la Edad Moderna. 1504-1525, Junta de Castilla y León, Valladolid, 2007.

78. Aparece como vecino de Toledo en 1503. Vid. AGS, RGS, VII-1503 $\left(1^{\circ}\right)$. Carta de abonos para fianza para Pedro de Monteser, vecino de Toledo. Su primera esposa, Francisca de León, debía ser vecina de Toledo, pues consta que llevó en dote una casa situada en esta ciudad, según declaraciones de testigos en AGS, EMR, HHII (=Hojas e Informaciones), 553-1º. 
contaba con 38 años $^{79}$. De hecho, según todos los indicios, debió abandonar Logroño muy joven, antes de haber tenido ocasión de despuntar en el desempeño de ninguna profesión, y el motivo de su marcha habría que buscarlo en la mala situación familiar. Así lo deducimos en concreto de las declaraciones de algunos testigos que, en 1516, manifestaron que el patrimonio que poseía en la capital riojana se componía de unas casas en la Calle de Villanueva, que había heredado de su madre, y de varias viñas y tierras que su padre le había dejado empeñadas, y él había logrado después desempeñar. Es decir, que básicamente lo que heredó de sus padres fueron deudas, y por ello no dudaría en abandonar muy joven su ciudad natal para buscarse un medio de vida mejor en otras partes del reino, recalando primero en Toledo, donde contrajo un primer matrimonio, al parecer con una doncella de modesta posición socioeconómica, pues sólo llevó en dote unas casas, para pasar después a Valladolid, donde casó en segundas nupcias con una mujer ya más acaudalada, perteneciente a una familia de mercaderes, con la que recibió una dote más sustanciosa, que debió, no obstante, devolver a su suegro tras la muerte de su esposa, al no haber tenido hijos con ella. Pero, a pesar de ello, su patrimonio personal después de esta forzada devolución de la dote de su segunda esposa siguió siendo considerable, puesto que nos consta que era propietario de valiosos inmuebles en la villa de Valladolid, y había tomado a censo perpetuo del convento vallisoletano de Santa Isabel algunos otros bienes rústicos, que integraban tierras de cereal y viñas. En contraste con este abundante patrimonio vallisoletano, las casas, tierras y viñas que conservaba en Logroño, después de haber cancelado las hipotecas que estaban cargadas sobre ellas, alcanzaban un valor mucho más modesto, alrededor de $70.000 \mathrm{mrs}$. Y esta constatación nos confirma, por tanto, que la carrera de este financiero de origen logroñés se desarrolló en su totalidad fuera de su tierra natal. Pero, a pesar de ello, conforme a una costumbre muy arraigada en la Castilla de la época, puso buen cuidado en no romper sus vínculos con la ciudad que le vio nacer, y por este motivo se esforzó por conservar el patrimonio heredado de sus padres.

Entre los vecinos de Logroño que mayor interés mostraron por el negocio de la recaudación de rentas de la monarquía, hasta el punto de tomar a su cargo rentas de gran envergadura, y notable complejidad en lo que a su gestión recaudatoria se refiere, cabría destacar para la primera mitad del siglo XVI a Bartolomé de Poza. Ciertamente no es mucho todavía lo que sabemos sobre la trayectoria profesional de este personaje, a quien, por un lado, encontramos con frecuencia realizando negocios de cambios en las ferias de Medina del Campo,

79. AGS, EMR, HHII, 553-1º. Información tomada en Valladolid, 26-XI-1516. Para esta fecha había enviudado ya de su segunda esposa, hija de Alonso López de Calatayud, vecino de Valladolid. 
mientras que, por otro, nos consta que asumió durante bastantes años la función de tesorero de la cruzada en el obispado de Calahorra y en el reino de Navarra $^{80}$. La operación de más envergadura en la que se embarcó fue, sin embargo, el arrendamiento del servicio y montazgo de los ganados en los años 1531, 1532, 1533 y 1534, para la que presentó como fiadores a algunos otros destacados hombres de negocios logroñeses, como Francisco de Gaona y la viuda de Juan de Gaona, Catalina de Yanguas ${ }^{81}$. Gracias a las averiguaciones que entonces se hicieron para determinar su solvencia financiera, conocemos con relativo detalle la composición de su patrimonio, que integraba un gran número de casas, en su mayor parte con bodegas, en la ciudad de Logroño, además de tierras para el cultivo del cereal, la vid y el olivo, en su entorno más inmediato, y otros bienes diversos, como censos cargados sobre diversas propiedades urbanas y rústicas, y la mitad de un molino ${ }^{82}$. A partir de esta información podemos concluir que se trataba de un individuo con muy buena posición económica, que poseía un patrimonio compuesto fundamentalmente de bienes inmuebles, en el que, por otra parte, alcanzaban una importancia relativa mucho mayor los urbanos que los rústicos. Es muy probable que la mayor parte de dicho patrimonio lo hubiese reunido mediante compras financiadas con los beneficios obtenidos de sus negocios financieros, pero la documentación consultada apenas nos ha permitido reconstruir los pormenores de dicho proceso.

Una posición mucho más modesta como financieros al servicio de la Real Hacienda ocuparon algunos otros vecinos de Logroño, que no pasaron de tomar a su cargo la recaudación de rentas en los distritos fiscales riojanos, y ni siquiera en calidad de arrendadores mayores, sino de simples tesoreros de las rentas encabezadas $^{83}$. Es el caso, por ejemplo, de Gonzalo Alonso de Navarrete, vinculado por matrimonio con la conocida familia de los Yanguas ${ }^{84}$, quien fue tesorero de las rentas encabezadas de las merindades de Rioja y Logroño en los años 1498, 1499

80. Entre otros documentos que nos lo presentan como tal tesorero Vid. AGS, RGS, III-1516 y IX-1519. Otras referencias mucho más tempranas confirman su especialización en el cobro de este impuesto de carácter eclesiástico. Así, por ejemplo, según consta en el acta de la sesión del cabildo de la catedral de Calahorra de 6-V-1501, en esta fecha dicho cabildo instituyó por su procurador al honrado Bartolomé de Poza, vecino de Logroño, para que en su nombre pudiese cobrar todos los padrones de las indulgencias y cofradía de la dicha madre iglesia, que en nombre de ella hizo publicar por este obispado el tesorero Francisco de Carrión.

81. AGS, EMR, HHII, 575-2 .

82. AGS, EMR, HHII, 565.

83. Sobre la introducción de los encabezamientos de alcabalas y tercias en la región riojana durante el reinado de los Reyes Católicos Vid. DIAGO HERNANDO, M., "La incidencia de la fiscalidad de la monarquía en el territorio riojano durante el reinado de los Reyes Católicos. Notas sobre la recaudación de las alcabalas", En la España Medieval, 30 (2007), pp. 173-215.

84. Vid. AGS, RGS, XII-1514. Beatriz de Yanguas, viuda de Gonzalo Alonso de Navarrete, había denunciado que a causa de estar viuda, algunas personas, y en concreto Hernán Martínez de Navarrete, le querían mover pleitos sin tener justicia para ello, para fatigarla. 
y 1500, presentando en aquella ocasión como sus fiadores a Gabriel de Viana y Juan Martínez Lobo, vecinos de Logroño ${ }^{85}$. Pero pocos años después fue él quien se ofreció como fiador de mancomún de su convecino Andrés de Ocaña, cuando se remataron en éste las rentas de la villa de Jubera y sus aldeas de los años 1504, 1505, 1506 y 1507, por un cargo de 40.000 mrs. anuales ${ }^{86}$. No es mucho lo que sabemos sobre su perfil socioeconómico, salvo que era originario de Navarrete, villa donde dejó en herencia a su esposa Beatriz de Yanguas un molino ${ }^{87}$. E igualmente nos consta que era hermano suyo un tal Diego de Baeza, que unas veces aparece en los documentos indentificado como vecino de Navarrete y otras como vecino de Logroño e incluso de Arnedo, el cual también realizó tímidas incursiones en el negocio de la recaudación de rentas de la monarquía, pues se le remataron en 1484 las alcabalas y tercias de la merindad de Logroño junto al judío Isaque Cohen, vecino de Alfaro ${ }^{88}$, y en 1485 y 1486, por puja del cuarto, las de los lugares de los hermanos del conde de Aguilar por 120.000 mrs. anuales ${ }^{89}$.

Prácticamente nada sabemos sobre Fernán Pérez de Salamanca, también identificado como vecino de Logroño, en quien se remataron en 1491 las alcabalas de Val de Arana, Villarreal de Álava y Santa Cruz de Campezo por 42.043 mrs..$^{90}$. Pero, dada la escasa envergadura de la renta y el carácter aislado de la noticia, no estimamos probable que destacase por su activa dedicación al negocio de la recaudación de rentas de la monarquía. Por su parte F.J. Goicolea nos informa que en 1480 las alcabalas y tercias de la ciudad de Logroño y su Tierra fueron rematadas por 317.000 mrs. en Alonso Martínez Moreno, su hijo Fernando Moreno, y Juan de Peralta ${ }^{91}$, pero apenas sabemos nada de momento sobre el perfil como hombres de negocios de estos tres individuos, al margen de la pertenencia de los dos primeros a una de las principales familias del estamento de los ciudadanos de Logroño.

85. AGS, Cámara-Personas, leg. 30. Carta de poder, otorgada en Logroño, 6-IV-1499, por Gabriel de Viana y Juan Martínez Lobo, vecinos de Logroño, a Diego de Baeza, vecino de Navarrete, para que les pudiese obligar como fiadores de Gonzalo Alonso de Navarrete, vecino de Logroño, hermano del dicho Diego de Baeza, por cuantía de 200.000 mrs., a Gabriel de Viana, y de 80.000 mrs. a Juan Martínez Lobo.

86. AGS, EMR, HHII, 549-1 ${ }^{\circ}$.

87. AGS, RGS, XII-1514. Provisión al corregidor de Logroño. Beatriz de Yanguas había informado que poseía un molino en los términos de Navarrete, y desde hacia poco tiempo Hernán Martínez de Navarrete, vecino de Logroño, con ciertos criados y otras personas, habían derribado una presa del mismo, dejándolo inutilizado para moler.

88. GOICOLEA JULIÁN, F. J., "Mercaderes y hombres de negocio...", p. 967. Según esta noticia en ese año aparece identificado como vecino de Arnedo.

89. AGS, EMR, HHII, 546. Presentó como fiador para esta operación a su hermano Juan Alonso, vecino de Logroño, quien según declaraciones de testigos tomadas en abril de 1485 poseía viñas en término de Logroño por valor de 200.000 mrs. y 110 fanegas de pan de renta en Ciruñuela y Santa Coloma, que se valoraron en 100.000 mrs.

90. AGS, EMR, HHII, 548.

91. GOICOLEA JULIÁN, F. J., "Mercaderes y hombres de negocio...", pp. 967-8. 
Mención especial merece el caso de Martín González de Yanguas, originario de esta villa serrana de la actual provincia de Soria pero que terminó fijando su residencia en Logroño, donde mantuvo ásperos enfrentamientos con influyentes sectores de la sociedad política local que desembocaron en el desafortunado episodio del incendio y destrucción de sus casas a comienzos del año 151992. Sabemos que estuvo muy vinculado a los condes de Aguilar, señores de Yanguas y de los Cameros, a los que sirvió durante bastantes años como contador. Y, precisamente esta vinculación es la que explica el hecho de que durante muchos años se hiciese cargo de la recaudación de las alcabalas y tercias en los lugares que formaban parte del estado señorial de los referidos condes, pues, por virtud de un acuerdo al que éstos habían Ilegado con los Reyes Católicos, se les reconoció el derecho a nombrar al recaudador de dichas rentas hasta que la monarquía les devolviese 5 millones de mrs. que le habían prestado ${ }^{93}$. Al margen de esta renta, no tenemos constancia, sin embargo, de que Martín González de Yanguas tomase a su cargo la recaudación de otras por cuenta de la Real Hacienda, por lo que cabe concluir que su interés por este negocio fue muy limitado, y se explica prácticamente sólo en función de su condición de contador de los condes de Aguilar.

Otros vecinos de Logroño de nivel socieoconómico más modesto sabemos, por fin, que tomaron parte en este negocio desde posiciones más netamente subordinadas, es decir, actuando como meros factores al servicio del arrendador principal. Es el caso en concreto de Francisco de Falces, quien tuvo cargo por Pedro de Santa Cruz, regidor de Aranda ${ }^{94}$, del cobro del alcabala del vino en esta villa burgalesa en los años 1502 y 1503. Según denuncia presentada después por su patrón, cometió entonces graves fraudes en el desempeño de su misión, pues se habría embolsado irregularmente en torno a 200.000 mrs., a base de hurtar a razón de 20 mrs. por cada cuba de las mayores, y 10 mrs. por cada una de las menores. Pero esta mala gestión no impidió que Pedro de Santa Cruz volviese a recurrir a él para encargarle de la recaudación de las alcabalas de Logroño en 1507, tarea en la que, a su juicio, de nuevo volvió a actuar de forma fraudulenta ${ }^{95}$.

En Santo Domingo de la Calzada estaba radicada la familia Ocio, cuyos miembros, además de desplegar una intensa actividad en el comercio de lanas,

92. Tenemos noticia de los conflictos violentos en que se vio involucrado Martín González de Yanguas en los años 1518 y 1519 en la ciudad de Logroño gracias a numerosas provisiones que se conservan en AGS, RGS.

93. Más detalles sobre esta cuestión en DIAGO HERNANDO, M., "La incidencia de la fiscalidad...".

94. Sobre la importancia de este individuo como arrendador de rentas al servicio de la monarquía en las últimas décadas del siglo XV y las primeras del siglo XVI Vid. DIAGO HERNANDO, M., "Arrendadores arandinos al servicio de los Reyes Católicos", Historia. Instituciones. Documentos, 18 (1991), pp. 71-95.

95. AGS, RGS VII-1513. Se recogen en este documento las denuncias presentadas por Pedro de Santa Cruz contra Francisco de Falces, por los fraudes cometidos en Aranda en 1502-3 y en Logroño en 1507. 
paños y otros productos, también destacaron por sus inversiones en el negocio de la recaudación de rentas de la monarquía en las primeras décadas del siglo XVI. Los tres miembros de la familia que más despuntaron en este terreno fueron los hermanos Sebastián, Cristóbal y Pedro de Ocio, que unas veces actuaron de forma individual, y otras formando compañía. Así, por ejemplo, el primero, Sebastián, fue arrendador de las salinas de Buradón en los años 1504, 1505 y 1506, aunque presentó como fiadores a sus dos hermanos, Pedro y Cristóbal ${ }^{96}$. Más adelante tuvo a su cargo las alcabalas de la merindad de Santo Domingo de Silos en $1511^{97}$, y las rentas por encabezar de las merindades de Rioja y Logroño de 1509, 1510 y 1511, para las que presentó como fiador a Martín Sánchez de Castro, vecino de Santo Domingo de la Calzada ${ }^{98}$. Por su parte tenemos noticia de que Pedro de Ocio fue arrendador de las alcabalas de Miranda de Ebro en compañía con Francisco de Frías ${ }^{99}$. Los tres hermanos conjuntamente tomaron a renta las alcabalas y tercias por encabezar de la merindad de Rioja de 1506, 1507 y 1508, presentando como fiadores a Martín Alonso de Ampuero, Alonso de Vergara y al escribano Juan de Ocio, todos ellos vecinos de Santo Domingo de la Calzada ${ }^{100}$. Y, por otra parte, en otras ocasiones se ofrecieron como fiadores de otros arrendores, como Rodrigo y Diego de Valderrama, vecinos de Frías, cuando éstos tomaron a renta las alcabalas y tercias de Santo Domingo de la Calzada y lugares de su merindad que estaban por encabezar en los años 1509, 1510 y $1511^{101}$.

Además de los Ocio, otras destacadas familias de Santo Domingo de la Calzada se mostraron interesadas por este negocio del arrendamiento de rentas de la monarquía, como atestigua, por ejemplo, la figura de Fernando Alonso de Valencia, en quien se remataron las alcabalas y tercias de las merindades de Rioja y Logroño en los años 1479 y $1480^{102}$. Y un panorama bastante parecido encontramos en la ciudad de Nájera, donde cabe destacar a la familia de los Salinas, a la que encontramos asociada con este negocio a lo largo de varias generaciones. Así, en 1457 Juan de Salinas obtuvo de Enrique IV la receptoría de la bula de la cruzada en el señorío de Vizcaya y provincia de Guipúzcoa ${ }^{103}$, que mantendría durante varios años, aunque finalmente parece que debió afrontar graves problemas de insolvencia, dado que en 1463 un juez ejecutor enviado por el rey procedió a vender en pública subasta algunos bienes muebles e inmuebles pertenecientes a él y a su yerno Pedro González de Belorado

96. AGS, EMR, HHII, 559-2.

97. Noticia en AGS, RGS, VIII-1514.

98. AGS, EMR, HHII, 559-1․

99. AChV, RE, 402-53 (9-X-1527).

100. AGS, EMR, HHII, 568.

101. AGS, EMR, HHII, 559-1․

102. GOICOLEA JULIÁN, F.J., "Mercaderes y hombres de negocio...", p. 967.

103. Íbid. pp. 966-7. 
por razón de deudas en que había incurrido con la Real Hacienda, al no haber atendido dos libramientos de los contadores mayores por cuantía de 800.000 mrs. ${ }^{104}$. Esta desafortunada experiencia no disuadió, sin embargo, a la familia Salinas de continuar invirtiendo en el negocio de la recaudación de rentas de la monarquía, y prueba de ello es que en la siguiente generación Diego de Salinas tomó a renta las alcabalas y tercias de Calahorra y de la merindad de Logroño de los años 1486 y 1487, que habían sido rematadas en Pedro de Santa Cruz y Alonso de Briviesca, vecinos de Aranda de Duero, quienes por su parte se las subarrendaron a él ${ }^{105}$.

En menor medida que en las ciudades de Logroño, Nájera y Santo Domingo de la Calzada, el interés por el negocio del arrendamiento de rentas de la monarquía también estuvo presente entre los vecinos de otros núcleos urbanos de la Rioja. Así, en Calahorra nos consta que uno de sus hombres de negocios más activos a fines del siglo XV y comienzos del siglo XVI, Sebastián de Bedoya, fue a comienzos de la década de 1520 fiador de los arrendadores del almojarifazgo mayor de Sevilla, una de las rentas de mayor envergadura de la Corona de Castilla ${ }^{106}$. Por su parte en Alfaro fueron miembros de la minoría judía los que mayor interés mostraron por este negocio, según atestiguan ejemplos como el de Mosen Abuzaque, quien tomó a renta las alcabalas y tercias de Calahorra y lugares de la merindad de Logroño en 1488, 1489 y 1490 en compañía con el arandino Franciso de Mena ${ }^{107}$. Pero, con carácter más excepcional, también encontramos individuos involucrados en esta actividad en núcleos de perfil más decididamente rural, como Cenicero, donde estaba avecindado un tal Martín García, en quien se remató inicialmente la renta de las salinas de Buradón de 1501, 1502 y 1503, aunque finalmente terminó siéndole arrebatada por Francisco de Salvatierra, vecino de Vitoria, tras efectuar una puja del cuarto $^{108}$.

\section{Conclusión}

Los mercaderes alcanzaron un notable protagonismo en la vida política de las ciudades riojanas a fines de la Edad Media y comienzos de la Edad Moderna, y también ocuparon una posición preeminente en la jerarquía social, que

104. AHN(=Archivo Historico Nacional), Clero, leg. 2970. Acta de una subasta de bienes efectuada en Nájera, 18-X-1463, ante Juan Martínez de Soria, escribano público.

105. AGS, RGS, VII-1493, fol. 186.

106. AGS, RGS, VII-1524. Referencia a la demanda presentada por Sebastián de Bedoya y su mujer Antonia de Velasco, en su condición de fiadores por los herederos de Hernando de Cuenca en la renta del almojarifazgo mayor de Sevilla.

107. AGS, EMR, HHII, 547. Presenta como fiadores a Lope de Frías, vecino de Alfaro, Don Aljoar, Açaçy Çerruque, Ayon y Mosse Çerruque, y a los hijos de Don Jaco Çerruque, todos vecinos de Alfaro.

108. AGS, EMR, HHII, 555. 
no tiene paralelo en la mayor parte de las grandes ciudades castellanas de la meseta, donde las familias dedicadas al comercio fueron relegadas a un segundo plano por las familias nobles que conformaban la oligarquía. Estas realidades traducen la importancia alcanzada por las ciudades de la Rioja como centros mercantiles en esa época, que en parte se explica por la herencia del Camino de Santiago y, en menor medida, por la localización estratégica de la región en la frontera con el reino de Navarra.

En el presente trabajo nos hemos propuesto profundizar en el conocimiento de las actividades desplegadas por los mercaderes que tuvieron fijada su residencia en estas ciudades en las últimas décadas del siglo XV y las primeras del siglo XVI, para avanzar en la caracterización de su perfil socioeconómico. El análisis realizado nos ha permitido comprobar que el comercio de la lana fue una de las actividades en las que mayor protagonismo lograron alcanzar, que les Ilevó a operar en un ámbito geográfico que sobrepasaba ampliamente los límites de la región riojana, pues incorporaba por un lado las sierras sorianas y burgalesas, y por otro, espacios tan distantes como Flandes, donde llegaron a instalarse algunos de ellos para trabajar allí como factores al servicio de sus colegas residentes en Rioja. En segundo lugar, también hemos podido identificar otros ámbitos en que desplegaron una notable actividad, como fue el del trato con paños y el del abastecimiento de carne para el consumo de la población urbana. La falta de noticias en la documentación consultada nos ha obligado, sin embargo, a dejar al margen muchos otros negocios que, con toda probabilidad, también debieron despertar su interés, y a veces en muy alto grado. A este respecto, cabe destacar, por ejemplo, que en el período analizado no hemos encontrado apenas referencias en la documentación relativas al trato con hierro por parte de los mercaderes riojanos, pese a que para momentos posteriores este negocio, asociado al del pescado, se ha considerado por algún autor como dedicación principal de todo un sector de la comunidad mercantil logroñesa ${ }^{109}$. No cabe duda de que son todavía muchas las cuestiones pendientes de clarificación, y es de desear que el avance en la exploración de las fuentes documentales disponibles, de momento insuficientemente explotadas, pueda permitir en un futuro más o menos próximo obtener una visión más completa y

109. Vid. BURGOS ESTEBAN, F. M., "Mercaderes e hidalgos. El poder en Logroño en el tiempo de los Felipes", en ENCISO RECIO, L. M., La burguesía española en la Edad Moderna, Universidad de Valladolid, 1996, p. 403. Según este autor cabe diferenciar tres grandes grupos entre los mercaderes logroñeses del siglo XVI: los dedicados al comercio lanero; los que comerciaban con especias y textiles, y los vinculados al hierro y al pescado. Otra noticia que también se ha de valorar en este contexto es la referida a la constitución por el mercader burgalés Diego de Bernuy de una compañía dedicada al comercio del hierro y herraje en la que participaba Diego Ximénez de Enciso, estante en Logroño. Vid. BASAS FERNÁNDEZ, M., "El mercader y regidor Diego de Curiel", Boletín de la Institución Fernán González, 150 (1960), pp. 166-7. 
matizada de la actividad desarrollada por los mercaderes de la Rioja en los siglos XV y XVI. Nosotros por el momento sólo hemos querido efectuar una modesta aportación a esta compleja empresa, aprovechando el material hasta ahora reunido a lo largo de dos décadas de trabajo en archivos, que es, por desgracia, escaso, parcial y disperso. 